University of San Diego

Digital USD

1991

\title{
An Analysis of Selected California Community College Faculty Members' Perceptions of Challenges Experienced during the First Year of Hire
}

Kristen M. Stonebreaker EdD, MA, BA

University of San Diego

Follow this and additional works at: https://digital.sandiego.edu/dissertations

Part of the Leadership Studies Commons

\section{Digital USD Citation}

Stonebreaker, Kristen M. EdD, MA, BA, "An Analysis of Selected California Community College Faculty Members' Perceptions of Challenges Experienced during the First Year of Hire" (1991). Dissertations. 564. https://digital.sandiego.edu/dissertations/564 


\title{
AN ANALYSIS OF SEIECTED CALIFORNIA COMMUNITY COLLEGE FACULTY MEMBERS' PERCEPTIONS OF CHALLENGES EXPERIENCED DURING THE FIRST YEAR OE HIRE
}

by

Kristen M. Stonebreaker, B.A., M.A.

A dissertation submitted in partial fulfillment

of the requirement for the degree of Doctor of Education

University of San Diego

1991

\author{
Dissertation Committee \\ Wallace Cohen, Ed.D., Director \\ Edward Kujawa, Ph.D. \\ Sharalee Jorgensen, Ed.D.
}




\section{ABSTRACT OF THE DISSERTFTION}

AN ANALYSIS OF SELECTED CALIFORNIA COMMUNITY COLIEGE FACUITY MEMBERS' PERCEPTIONS OF CHALLENGES EXPERIENCED DURING THE FIRST YEAR OF HIRE

This study examined the challenges and sources of support encountered by new faculty the first year of hire. Nineteen participants were interviewed from three community colleges. Interview sites were chosen to include three institutions of different sizes. Site 1 was an urban-centered college and a part of a multi-college district. Sites 2 and 3 were both single-college districts. All participants were hired in the Fall of 1989, and were full-time, tenure-track, teaching faculty. Interviews were audiotaped and analyzed by the researcher. From participant comments, themes were generated and summarized in frequency response tables.

Some of the major findings of the study were: first, instructors having no previous community college teaching experience reported problems with student diversity within the classroom; the number of teaching hours; and emotional isolation with regard to colleagues the first year of hire. Next, the size of the employing school affected the problems new faculty experienced with regard to student diversity, teaching load, and collegial relationships. Third, the amount of previous teaching experience did not play a significant role in the types of problems reported, but the 
type of experience did. Finally, proximity and likeness of purpose seem to play a major role in perceived sources of help the first year of hire. Most respondents named department colleagues as their primary source of help the first year.

Some of the major recommendations of this study were: (a) give new faculty the opportunity to evaluate the orientation program; (b) break orientation information into modules of three or less hours; (c) arrange orientation modules according to participant needs; (d) give new faculty a tour of the campus, satellite centers, and the surrounding community; (e) avoid giving new faculty "leftover" teaching hours; (f) place the new instructor's office in close proximity to department colleagues and staff; $(g)$ encourage college staff to assume a mentoring attitude toward new faculty; (h) give assigned mentors and their proteges released time; (i) provide mentor training; (j) use tenured faculty as mentors. 


\section{ACKNOWLEDGEMENTS}

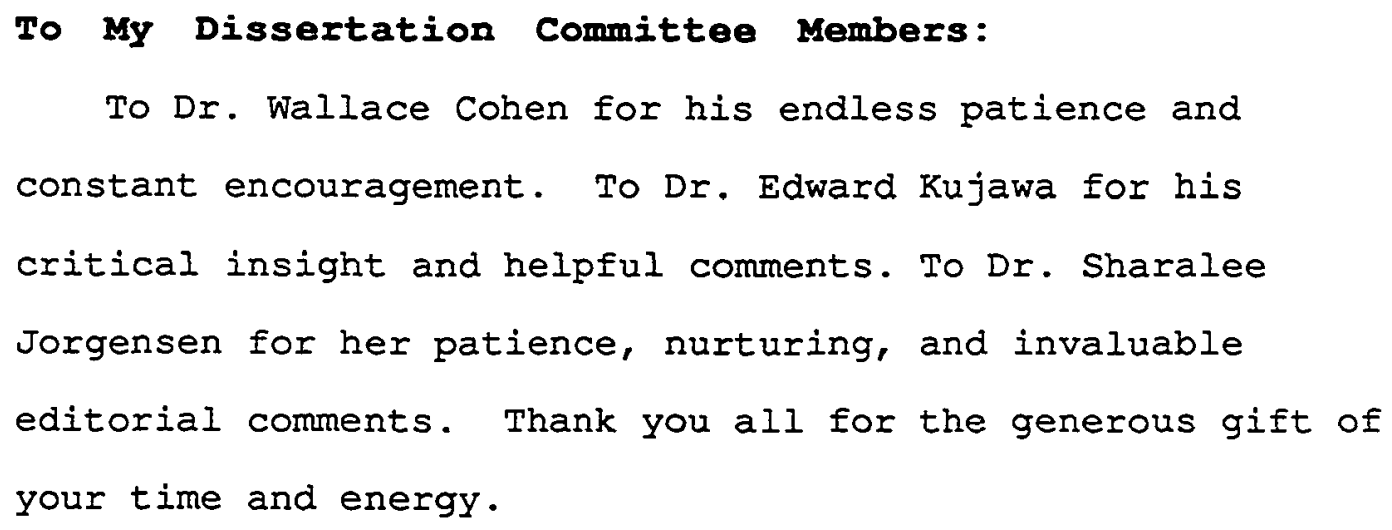

To my Mom and Dad for teaching me the value of education early in life. To my brothers and sisters whom I've neglected this past year. To my extended family of friends and relatives who, by understanding, provided great encouragement to finish this project.

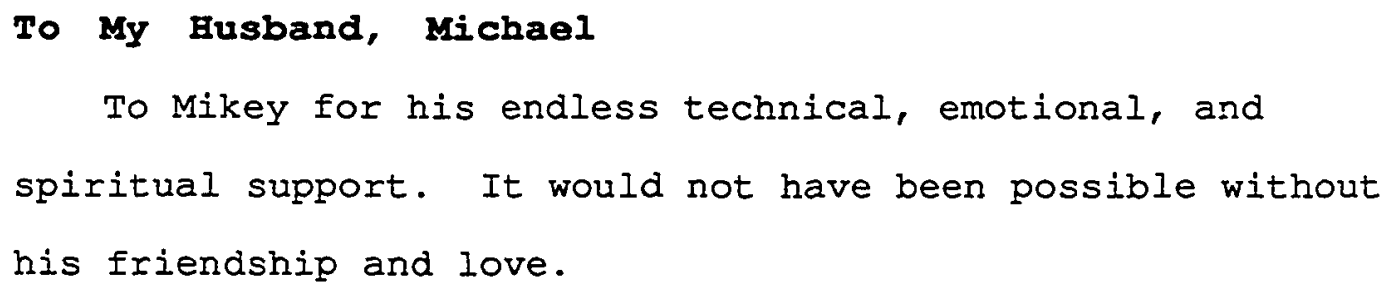




\section{TABLE OF CONTENTS}

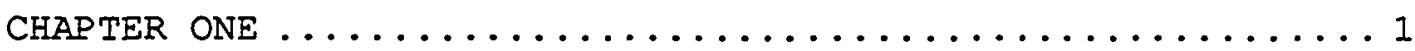

Statement of the Issue ....................

Int roduction $\ldots \ldots \ldots \ldots \ldots \ldots \ldots \ldots \ldots$

The Problem $\ldots \ldots \ldots \ldots \ldots \ldots \ldots \ldots \ldots \ldots \ldots$

Need for the study ..................4

Purpose of the Study ................. 5

Significance of the Study ..............

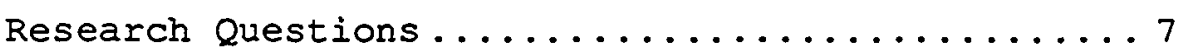

Design of the study $\ldots \ldots \ldots \ldots \ldots \ldots \ldots \ldots$

Limitations ....................... 10

Organization of the study ..............11

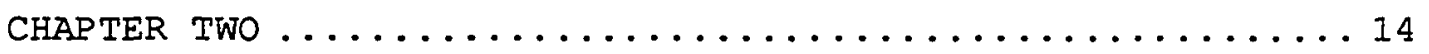

Review of the Iiterature ................. 14

Introduction ..................... 14

Secondary and Elementary School Teachers...... 15

Teacher Induction.............. 15

Mentor Programs.................. 17

Four-Year University Faculty ............ 18

New-Faculty Orientation............ 19

New-Teacher Teaching Orientation........ 21

Faculty Perceptions and Attitudes....... 22

Community College Faculty .............. 27

The Community College Movement........ 27

iii 
California Community College Movement..... 29

Student Diversity.................... 31

Community College Full-Time Faculty...... 34

Faculty diversity and attitudes..... 34

New-Teacher Preparation............. 38

New-Faculty Orientation ...........4

New-Faculty Workshops............43

Summary ..................... 47

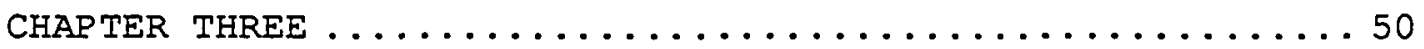

Research Design and Methodology .............. 50

Introduction ....................... 50

Validity Issues................ 52

Data Collection Sites................. 53

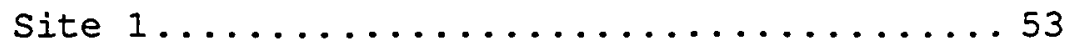

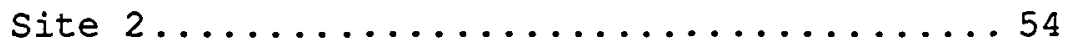

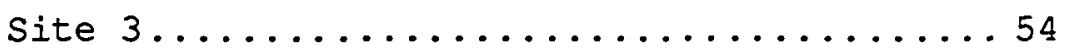

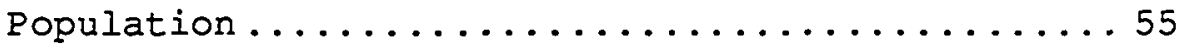

Risk Management Procedures........... 56

Participant Selection............. 56

Instrument ....................... 57

Data Analysis ..................... 58

Summary .......................60

CHAPTER FOUR $\ldots \ldots \ldots \ldots \ldots \ldots \ldots \ldots \ldots \ldots \ldots \ldots \ldots \ldots \ldots \ldots \ldots \ldots$

Findings $\ldots \ldots \ldots \ldots \ldots \ldots \ldots \ldots \ldots \ldots \ldots \ldots \ldots \ldots \ldots \ldots \ldots$

iv

Reproduced with permission of the copyright owner. Further reproduction prohibited without permission. 
Introduction ...................62

Response Rates....................63

Interview Question one..............63

Interview Question Two ..............66

Students....................67

No problem................67

Student reasons / motivation for

participation...............67

Quality of day vs. night students....69

Student skill levels...........69

Student ethnic diversity.........70

Teaching Load Challenges............ 71

Load too heavy............... 71

Full-time load easier to manage......72

Load manageable but challenging..... 72

Teaching load reduced first

semester.................73

Teaching hours awkwardly arranged....73

Collegial Relationship Challenges.......74

Isolation, physical and emotional....75

Relationships with other department

members................. 76

Fitting into the department

structure................76

Responsibility to the department.....77

V 
Administration or College Governance

Challenges ..................... 78

Politics................. 78

Shared governance.............80

Evaluation/tenure process.........82

Credibility of the individual with

administrators............... 83

Funding................. 84

Eaculty Organization Challenges........ 85

Time spent on committees........85

Eaculty labor unions............ 85

Other challenges............86

Interview Question Three...........86

Colleagues..................... 87

Department Chairperson............. 89

Department Secretary...............89

Division Dean................... 90

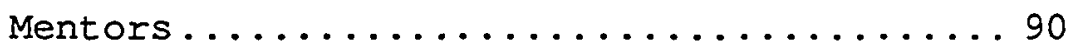

Interview Question Four............. 91

Orientation to the Institution.........91

Shorter orientation segments.......91

Develop a schematic chart of college

levels.................... 92

Organize a peer support group for

new faculty.................. 92

vi 
Conduct a tour of the campus and community................ 94

Outline services available to students.................. 94

Give a verbal overview of the faculty manual............... 94

Hold a separate orientation session

for new faculty.............. 95

Show a film about the college and

its history................ 95

Offer a workshop about the community college system..............96

Suggestions for the Department.........95

Orientation for part-time to fulltime faculty.............. 96

Reduce the first semester teaching load........................96

Office in close proximity to the department................ 97

Handbook of "how-to's"...........97

More orientation to the department...998 Explain the political structure of the department................ 98 Suggestions Regarding Tenure and Evaluation........................99 Suggestions for the Use of Mentors....... 100 vii 
The Research Questions Answered........... 102

Research Question One............. 103

Students.................... 103

Teaching load................ 104

Collegial relationships.......... 104

Administration or college

governance.................... 105

Faculty organization challenges..... 106

Research Question Two...............106

Students................. 107

Teaching load............... 107

Collegial relationships......... 108

Administration or college

governance................... 109

Faculty organizations........... 110

Research Question Three.............111

Students................... 112

Teaching load................113

Collegial relationships.......... 114

Administration or college

governance..............116

Faculty organizations........... 116

Research Question Four.............118

Summary ....................... 118

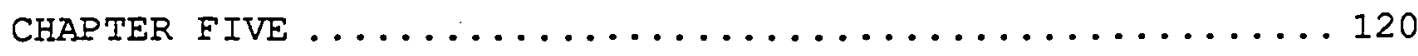

Summary, Conclusions, and Recommendations........ 120

viii 
Introduction ..................... 120

Summary ........................ 121

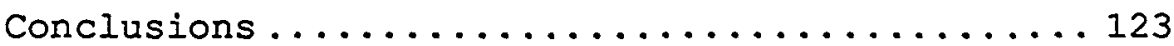

Independent Variables............. 123

Participant Suggestions............. 124

Student diversity............. 124

Teaching load................ 125

Culture and politics........... 126

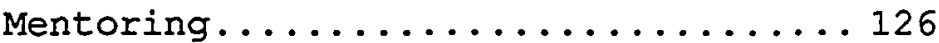

New-faculty support groups........ 128

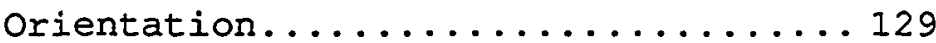

Recommendations ................... 132

Implications for Further Research ........ 136

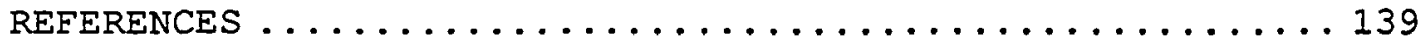

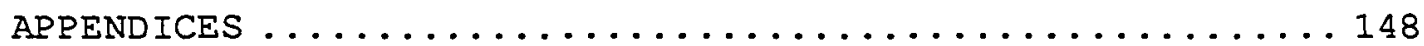




\section{IIST OF TABLES}

Table 1: Participant Teaching Experience............64

Table 2: Participant Teaching Experience Presented by

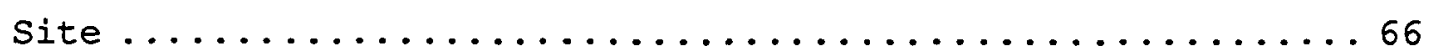

Table $3:$ Student Diversity Challenges .............68

Table $4:$ Teaching Load Challenges ................ 71

Table 5: Collegial Relationship Challenges ...........74

Table 6: Administration or College Governance

Challenges $\ldots \ldots \ldots \ldots \ldots \ldots \ldots \ldots \ldots \ldots \ldots \ldots \ldots \ldots \ldots$

Table 7: Faculty Organization Challenges ........... 85

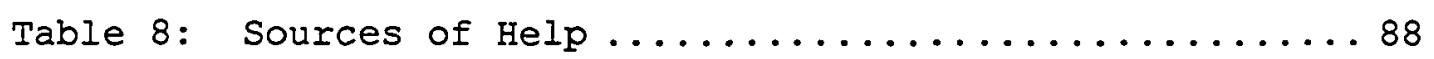

Table 9: Suggestions for Orientation to the

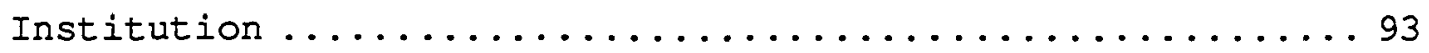

Table 10: Suggestions for Orientation to the Department .............................. 97

Table 11: Suggestions Regarding Tenure and Evaluation .... 99

Table 12: Suggestions Regarding the Mentor Program..... 101

Table 13: Student Diversity Challenges Presented by

site .................................... 107

$\mathbf{x}$ 
Table 14: Teaching Load Challenges Presented by Site ... 108

Table 15: Collegial Relationship Challenges Presented

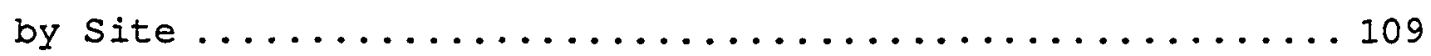

Table 16: Administration or College Governance

Challenges Presented by Site ................. 110

Table 17: Faculty Organization Challenges Presented by

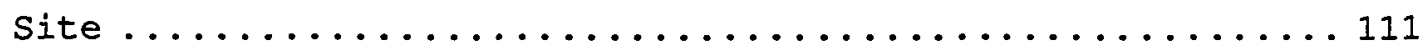

Table 18: Students Diversity Challenges Presented by Participant Teaching Experience ............... 113

Table 19: Teaching Load Challenges Presented by Participant Teaching Experience ................ 114

Table 20: Collegial Relationship Challenges Presented by Participant Teaching Experience ............... 115

Table 21: Administration or College Governance

Challenges Presented by Participant Teaching Experience .. 117

Table 22: Faculty Organization Challenges Presented by Participant Teaching Experience ............... 118 


\section{IIST OF APPENDICES}

APPENDIX A: Telephone Contact ................ 148

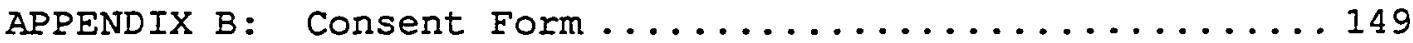

APPENDIX C: Interview Questions ............... 150 


\section{CHAPTER ONE}

Statement of the Issue

Introduction

The mid to late $1800^{\prime}$ 's was a time of decided unrest among most rural Americans, a disturbance caused by a desire for more and better education, and a need to engage in some form of self-expression (Horner, 1954). It was during this time that the responsibility for individual education shifted from the family to the school. Prompted by social forces calling for trained industrial workers and a general drive for social equality, the Morrill Act of 1890 was passed and the community college concept was born.

Initially, most community colleges were agricultural institutions or teacher training colleges that provided a lower cost alternative to the private university. They sought to solve a variety of social ills: racial integration, unemployment by providing training for jobs, and social stratification by teaching technology to the masses (Cohen and Brawer, 1982).

The Problem

This diverse focus of the community college has not changed significantly in the last 100 years. Cross (1983) maintained that community colleges possess an eclectic nature 
that results in multi-goaled curriculum. That is, most schools are a combination of four-year transfer classes, vocational training, and adult education courses. Similarly, Cohen and Brawer (1982) added the observation that community colleges also incorporate remedial education and community service responsibilities.

The community college system is one of the fastest growing segments of American education. Wisniewski (1990) projected that by the year 2005 there will be 18,000 new faculty positions in California alone. These positions will be generated by the expansion of existing campuses, and by the construction of at least 16 new community colleges. The impetus for this building boom is the estimate that in the next 15 years California student enrollment will soar from the current 1.4 million to 1.8 million students.

Roueche (1989) contended that in the next 10 years, "the average American community college must replace forty to sixty percent of its faculty, support staff, and administrative leadership team" ( $p .10)$. If Rouche is right, the next decade will bring an influx of new faculty. This study will help college leadership to meet the needs of this growing populous of new faculty members.

Each new faculty member will be forced to cope with not only the eclectic nature of the community college, but with the diverse make-up of its student body. Cohen and Brawer (1982) stated that community colleges tend to be commuter 
schools and as a result experience several special problems. First, most teachers have in their classrooms a combination of full and part-time students. This situation usually results in varying levels of motivation among students. Second, community colleges have an open door admissions policy which prompts additional classroom challenges. For example, teachers find that they must often teach to the median level of subject competency within a single class. Also, there tends to be a higher attrition rate that can lead to a lower level of satisfaction for the teacher who is not able to see his/her student achieve successful course completion.

Demographics and the changing socio-economic environment also contribute significantly to the type of student taking classes at a community college. Along with the traditional student (those enrolling immediately after high school), college campuses are enrolling the non-traditional or reentry student. This type of student includes adults reentering the education system after an absence of several years, parents with children in school, senior citizens still active in retirement, and people who work during the day and attend college at night for the purpose of job advancement.

This study will. focus on the first-year challenges of full-time community college faculty. These challenges are generated, in part, by the unique nature of the community and the student populous it services. 


\section{Need for the Study}

Given the unique nature of the community college, the diverse make-up of its student body, its continued growth, and its place in a constantly changing educational and social environment, more data need to be gathered about the faculty involved in carrying out the community college mission and philosophy. Specifically, the critical first year of hire needs to be explored with the intention of uncovering effective ways to meet the needs of first-year faculty. In support of this point, Kiechel (1988) and Geromel (1989) pointed to the importance of an employee's first few months, even days, of employment as a critically influential period. They noted that long-lasting attitudes are usually developed during this time frame.

Cohen, Lombardi, and Brawer (1977) criticized research in the field of education and stated that most studies are a compilation of demographic variables focused on "number, age, ethnicity, number of siblings and progeny, and educational level of the parents" (p. 113). The study reported herein supplements educational literature with a descriptive approach that goes beyond the standard demographic analysis. Brawer (1968) suggested that no one approach can be used for understanding a faculty member. Thus, this study adds a new and different piece of knowledge to the body of research examining the needs of first-year faculty. 
Researcher interaction with college administrators supports the need for this study. The focus for this research sprang from and was developed by the ideas offered by selected community college administrators and chief instructional officers. In informal interviews these administrators described possible research studies whose findings, they thought, could help them as instructional officers. A compilation of their input built the dissertation proposal and later the dissertation study. Purpose of the study

The research reported herein yields new and insightful data. This study gathers data about first-year experiences-as personally described by selected new community college faculty members.

As previously noted, this researcher conducted informal interviews with three community college administrators when formulating the dissertation proposal. An interesting observation surfaced during these interviews. The observation focused on the fact that one administrator reported that she relied largely upon her personal experience when developing new-faculty support programs. That is, she designed the programs to address the problems she had personally experienced as a new faculty person. This observation is not particularly surprising, but it does show how this study may contribute significantly to the data base 
used by some administrators to build orientation and other assistance programs for new faculty.

\section{Significance of the study}

The findings of this study should benefit anyone interested in assisting new faculty members. College administrators, department staff, and other faculty will find in its conclusions and recommendations a source of information focused on the perceived problems and sources of support given to new hires.

In a broad sense, the knowledge presented in this study allows college leaders to better understand the needs of new faculty and to improve support services to them. By helping new faculty through the often turbulent first year of hire, college leaders will, in turn, provide better service to students in those teachers' classrooms.

Experience is a powerful teacher. One way that educational research can benefit from personal experience is to study the experience qualitatively. This means that those involved in the phenomenon are asked to describe it. An analysis of data could yield common experiences or themes that would give administrators a better understanding of first-year faculty needs; thus improving faculty effectiveness to the community college, the students they teach, and to our collective society.

Berlak and Berlak (cited in Foster, 1986) wrote that the primary role of administrators should be to "to raise 
questions about preferences of the community and of teachers that are normally taken for granted, and to assist in a search for alternatives; in other words, to encourage critical inquiry" (pp. 192-193). This study searches for alternatives to the standard orientation and treatment of first-year faculty. By asking new faculty to talk about their challenges, sources of support and the advice they would give to the institution, this research adopts a critical inquiry stance.

\section{Research Questions}

To explore the challenges experienced by first-year community college teachers, the following research questions were developed.

1. What problems did new faculty experience in each of the following categories:
a. Students
b. Teaching load
c. Collegial relationships
d. Administration or college governance
e. Faculty organizations

2. Did the size of the employing school affect the kinds of problems experienced?

3. Did the amount of previous teaching experience affect the kinds of problems experienced?

4. What kinds of things (people, programs, etc.) did new faculty name as being helpful during the first year of hire? 


\section{Design of the study}

The nature of this study is descriptive. It is an exploratory project and does not attempt to develop an inclusive description of new-faculty needs in all institutions. Its intent is to study the phenomenological experiences of first-year community college teachers and to focus on the challenges and sources of help given the first year of hire. In keeping with the methodology recommended to examine a phenomenon, an interview instrument was used to gather data.

A thematic interview guide was developed and used during each interview session to insure that all research focuses were addressed. Each interview was audiotaped, to aid with content analysis of the data. Responses were analyzed by the researcher, grouped into themes, and reported in response frequency tables. A narrative explaining participant responses supplements each table. Although the data are reported in aggregate form, quotes are used to provide clarity and emphasis.

Nineteen participants from three community colleges were interviewed. Interview sites included three schools of different sizes. Site 1 is an urban-centered college and a member of a multi-college district. At the time of the study interviews, it employed 150 full-time faculty and serviced 13,000 students. Site 2 is a suburban, single-college district and at the time of the study interviews employed 260 
full-time faculty and serviced 19,000 students. Finally, Site 3 is a suburban, single-college district and at the time of the study interviews employed 100 full-time faculty and serviced 8,000 students. All participants were hired in the Fall of 1989, and were full-time, tenure-track, teaching faculty.

Thirty-four instructors qualified as participants in this study. By site, that number breaks down as follows: Site 1, 17 instructors were hired in the Fall of 1989 on a tenuretrack basis, eight were selected using a random draw, shuffled deck method. Site 2, six instructors met eligibility requirements and five participated in the study; one instructor declined because of time constraints. Site 3 , eight instructors were contacted and six accepted; two instructors declined because of time constraints.

Eison and Hill (1990) recommend the type of study used in this research project. They suggest that when designing workshops for new faculty, the designer should "interview junior faculty to identify their concerns--the personal and professional needs of new faculty are most easily recalled by junior faculty and their input in establishing objectives and creating activities should be sought" (p. 231). The study reported herein pools the collective input of several new faculty. Because of the data reported, administrators should have a greater insight into ways to support and make successful first-year faculty. 


\section{Limitations}

The primary research instrument in this study is the researcher as interviewer; the primary method, the interview. The study has strengths because the data are descriptive and rich due to direct and personal contact with informants--the experts in the phenomenon. All studies incorporate an error factor. In this study the researcher is the only instrument and there is naturally a greater chance of error within the findings. Husserl (cited in Tesch, 1984) maintained that the researcher must approach the phenomenon under consideration without preconceived notions. This meant that the researcher was aware of his or her own presuppositions and tried not to permit them to influence the data analysis. Thus, the presuppositions were "bracketed." In this study, the researcher carefully accounted for and bracketed preconceived ideas and/or biases, but it is naive to assume that they did not come into play at any time during the study.

The thematic interview guide and the interview session itself are other possible researcher-based sources of error. For example, each participant was asked the same general questions and it is possible that the wording of the questions as written influenced responses. In addition, with each interview the researcher experienced a growing sense of confidence and it is likely that follow-up questions within each session became more articulate and probing as familiarity with the questions and the process grew. 
This research assumes that respondents answered questions honestly and candidly. Also, interviewees reflected on the first year of hire approximately eighteen months after the hire date. There is a possibility that participant reflections may be inaccurate or tainted by time. The comments of interviewees form the basis for all conclusions and recommendations. Thus, there is the slight possibility that misinformation given to the researcher found its way into the research conclusions.

A final limitation to this study is in its relatively small number of participants. Tesh (1984) stated that typically phenomenological studies include 10 to 15 participants. Although this study includes nineteen participants, the number is hardly representative of the entire population.

Because of these limitations, readers should regard this study as an exploratory project. It is not intended to be descriptive of the entire populous, but to present an indepth look at the challenges encountered by nineteen, community college new hires.

\section{Organization of the Study}

This research project is presented in five chapters. Chapter One provides an overview of the impetus for the project and outlines the significance of the study as it addresses the research need. Also in this chapter, the 
research questions are outlined and the study design discussed.

Chapter Two presents the theoretical foundation for subsequent chapters. To this end, literature about new faculty is explored from the vantage point of three different sectors of education: elementary and secondary teachers, university faculty, and community college faculty. Also in this chapter is a history of the community college system that is included to provide background understanding of the complex nature of the problem being studied.

The third chapter explains the research methodology and discusses the research design. Also in this chapter is a description of subjects, and an explanation of the procedures and methodology employed in the collection and analysis of data.

The research findings are presented in Chapter Four. Through the use of tabular and narrative summaries the research questions are revisited and answered.

Chapter Five offers first, a summary of experiential themes as extracted from participant responses; second, a listing and discussion of several conclusions drawn from the responses; third, recommendations for possible action by college leaders; and finally, implications for further research.

In the following pages a study will unfold. The study is unique and describes a phenomenon experienced by all new 
faculty. Its data will yield findings and conclusions that fill research needs articulated by not only educational literature, but also by community college instructional administrators. 


\section{CHAPTER THO}

\section{Review of the Literature \\ Introduction}

Research addressing the challenges faced by full-time community college faculty is minimal. The idea that neophyte instructors require special attention is not new; however, little research is done to describe the special needs of first-year community college faculty. As a result, this review examines a number of related areas to build a foundation for understanding the import of this study as it contributes to the body of research about the special needs of new faculty in general, and specifically community college instructors.

To this end, three research areas will be examined: elementary and secondary teachers, four-year university faculty, and community college faculty. These broad topics provide a method for grouping similar research, but more importantly piece together an understanding of a theme that is of concern to all sectors of education--what are the anticipated needs of the newly hired and how can they best be indoctrinated into the system?

The computer search services of the Educational Resources Information Center (ERIC) and Dissertation Abstracts provided 
most of the literature examined in this review.

Additionally, bibliographic sources provided leads to relevant material often obtained through interlibrary or private party loan. The libraries of the University of San Diego, San Diego State University, and Palomar Community College were used extensively in this literature search.

\section{Secondary and Elementary School Teachers}

Researchers in the $1980^{\prime}$ 's generated a significant amount of research about first-year elementary school teachers. This research focused on the special problems or challenges associated with being a new instructor and outlined induction and mentoring programs designed to meet the needs of new teachers. Although studies about secondary school faculty report findings that obviously are not meant to impact on community college faculty research, this researcher has found that several issues explored are similar if not identical with the issues embraced by this dissertation. Thus, a look at a portion of secondary school research is warranted and germane.

Teacher Induction

Quisenberry (1989) published an annotated bibliography of about sixty journal articles and ERIC documents. This fiveyear look at research on teacher induction was organized into six sections: (a) teacher education--general; (b) characteristics/needs of beginning teachers; (c) mentors and mentor relationships; (d) university induction programs; (e) 
assessment and evaluation of induction programs; and (f) annotated bibliographies, monographs, papers and reports on teacher induction.

Marshall (1988) wrote that it was important that firstyear teachers are given non-judgmental support. As a result of her research, she concluded that opportunities to reflect, inquire and problem solve with others experiencing similar challenges, and with an experienced non-evaluating educator, should be given to all first-year teachers.

Wasserman and Emory (1989) described two models of newteacher support developed in the Department of Elementary Education at California State University, Northridge. Although different, both models were built on the same assumption: that new-teacher support must be responsive to the context where actual teaching takes place and that support must be responsive to the needs expressed by the new teacher.

Boccia (1989) studied the professional concerns of beginning teachers. She surveyed 71 secondary certification graduates after their first three years of teaching. The focus of the study was to determine: (a) instructional concerns of beginning teachers; (b) non-instructional concerns; (c) the kind of help they wanted; (d) nature and extent of orientation given; and (e) support available on the job. Respondents reported moderate to high classroom concerns and moderate concerns about understanding the 
contextual norms for their schools and communities. Finally, beginning teachers reported successes in many of the same areas in which they reported concerns and showed interest in professional assistance targeted toward them.

\section{Menter Programs}

The mentoring of first-year teachers by experienced faculty has been widely addressed in the literature about secondary school faculty. Heck and Blaine (1989) described the effects of a pairing induction program of 15 first-year teachers and 15 mentors. The site of the study was a school district chosen because of its unusually high teacher turnover, the cultural diversity of the students, and the large number of beginning teachers. Beginning teachers were matched with mentors according to school, grade level, subject areas, and personal characteristics. Mentors and beginning teachers identified the following as important first-year problems: classroom management, finding and using support resources, motivating students, working with special problems and developing positive relationships with parents, teachers, and administrators.

Blair and Bercik (1987) asked 26 experienced teachers their perceptions of the process of teacher induction in their districts and ways to improve it. Most of the respondents agreed that the assignment of a mentor or support teacher was a major priority. In response to the question of a first priority for orienting new teachers, a majority of 
the experienced teachers felt that helping beginners with classroom management and discipline was the first priority. The need for formal training for mentor teachers emerged as an important conclusion in this study.

The amount of research devoted to understanding and supporting new teachers in the secondary school system is substantial and noteworthy in its attempt to shed light on the special needs of new teachers. Within the brief overview presented above, one can see two recurrent research conclusions. One, it is important that new teachers have access to sources of support that help them to adjust to challenges often inherent in the first year of hire. These challenges include: Classroom management; finding and using support resources; dealing with student diversity; and developing positive relationships with parents, other teachers, and administrators. The second emergent theme centers on the use of mentors as a major part of new-teacher induction. Both are revisited in the next part of this review as research about four-year university faculty is explored.

\section{Eour-Year University Eaculty}

The second part of this literature review looks at fouryear university faculty. The same rationale applies with this review section as did with the last, that although the studies provide insight into four-year college faculty, the findings are related and possibly applicable to faculty hired 
by two-year colleges. The studies examined next build a knowledge base about faculty in the higher education system. New-Faculty Orientation

Almost twenty years ago, Sutton and zion (1973) built a solid case for the development of a new-faculty orientation program. They maintained that a strong orientation program would not only equip the new member to perform assigned job duties, but would benefit each member of the institution as well.

As a part of new-faculty orientation, Knowles (1970) wrote that each new full-time faculty member deserved serious attention from the department chairperson and senior faculty members. He felt that this attention was likely to result in immediate new-faculty productivity. Knowles maintained that the extra attention given by the department chair and senior faculty members would hasten the newcomer's learning how things were done around the department, thus providing an indoctrination to the culture of the college. Similarly, Waggaman (1983) advocated that new faculty have an informal and private counseling session with the department chair and selected senior faculty members. The purpose of this session is to explain to the new instructor how to get things done successfully without becoming trapped in a destructive conflict (p. 46). Waggaman explained that one of the first attitudes that needed to be communicated to the new faculty member is that he or she is expected to seek an active and 
rewarding career in academe. Success in this endeavor necessitated an understanding of not only the sources of rewards, but also a knowledge of the means to achieve rewards (p. 53).

Sawma (1989) outlined the formal, new-faculty orientation program used by Kirkwood University. She wrote that newfaculty orientation is a two-part process. Part one begins with the president's address that describes the university's mission, philosophy, and programs/activities in progress. Following the president's speech, current employees of the university share their experiences and feelings about Kirkwood. Presenters relate positive as well as negative experiences. The second part of orientation is actually a self-selection process. Booths and tables are staffed by various departments and participants are given the opportunity to select tables of interest and meet one-on-one with a department representative. Departments represented are typically: payroll, personnel, affirmative action, media services, library services, counseling services, wellness programs, insurance programs, staff development activities, employee unions, bookstore services, and printing services. During this time refreshments are served and the climate according to Sawma, is social, active, and participatory.

An increasingly popular theme in discourse about new teachers at four-year universities is the idea that new instructors frequently struggle with a gap between subject 
area expertise and effective teaching (Eison and Hill, 1990). Noonan (1980); Lewis, Svinicki and Stice (1985); and Eison (1989) described programs that are designed to take the new Ph.D.from being a successful student to being an effective teacher. Each of these programs are discussed in greater detail in the next section. New-Teacher Teaching Orientation

Noonan described an annual three-day retreat for newfaculty members from four colleges in the Central Pennsylvania Consortium. Held between semesters, it is attended by 10 to 15 faculty members in their first year of full-time teaching. Topics addressed by program activities included: videotaped mini-lectures, learning how to lead discussions, and identifying and examining assumptions about teaching and learning.

Lewis, Svinicki and Stice are all members of the Center for Teaching Effectiveness at the University of Texas at Austin. These professionals developed a week-long, presemester, voluntary seminar for new faculty members. Designed to introduce participants to the basics of teaching, the program centers on the following questions and areas: effective teaching--what is it?; alternative teaching modes; improving specific teaching techniques; learning theory; communication skills; testing and grading; and evaluating teaching. 
Finally, Eison described the resistance incurred and the solutions developed with instituting a week-long, presemester, mandatory program for all new faculty members at Southeast Missouri State University. Over a two-year period, a number of adjustments were made to deal with specific problems generated by the mandatory requirement. These adjustments included: a pre-program survey, conducted to determine the background and experience level of participants; addressing basic orientation issues; providing more free time during the program; flexibility within the program format to meet the needs of participants.

Thus far, different orientation concerns for new fouryear faculty have been described. The next type of study addressed is one that gives descriptive insight into how new instructors view themselves during and after the first year of hire.

\section{Eaculty Perceptions and Attitudes}

Fink (1984) conducted a study of 97 beginning college teachers, one-third of which had participated in a teaching preparation program in their doctoral work. All participants were new faculty in a four-year university. The study consisted of both a qualitative and quantitative focus, in that participants all answered four questionnaires at different times during the first year, had one or more of their courses evaluated by students, and had their chair and two colleagues answer questionnaires. In addition, 30 
participants were interviewed and observed in the classroom. Some results of data analysis are: non-tenure track appointments frequently lead to poor teaching and low personal satisfaction, teaching loads with several different subject matter preparations also reduce teacher performance and satisfaction, teacher training programs in graduate school are effective--for those who expect to benefit from them, and new teachers do not perform as well as more experienced instructors--but not significantly so.

Some long-term implications outlined by Fink are that the vast majority of participants had a strong desire to be effective teachers by the end of the first year. Second, most respondents with non-tenure track appointments found themselves faced with a degree of uncertainty about their job future and this negatively affected their teaching effectiveness. Third, most respondents were given a teaching overload the first year. Consequently, new teachers developed a teaching style that was rushed with no time for creative reflection on how to teach effectively and no time to seek help in this regard.

Turner and Boice (1989) conducted interviews with new tenure-track faculty and full-time lecturers hired by a fouryear university. Their purpose was to pinpoint new-faculty perceptions about: recruiting and orientation practices; classroom, research, and scholarly writing pressures; socialization to departmental and campus mores; the stresses 
and satisfaction of new-faculty status; and senior faculty as sources of collegiality and intellectual stimulation.

Interviews took place over a two-year period (the first four semesters of hire). A randomly selected subsample of 10 new faculty were actively observed in their offices or in the classroom. In addition, these 10 people kept daily logs about how they spent their time and about their personal reactions and feelings.

Research findings indicated that most new faculty did not learn about their position through The chrogicle of Higher Education, but instead through discipline specific media. In addition, most had strong and lasting distress over what they perceived as unprofessional treatment during recruitment and interviewing interactions.

Other findings showed that $83 \%$ related a level of "busyness" that resulted in stress related symptoms. With regard to teaching, those who received negative student evaluations within the first two years of teaching reported that they felt motivated but insecure in their knowledge and skills. Next, in response to questions about scholarship, almost all described themselves as highly motivated to be productive scholars. They felt that they were hard working, patient, persevering etc., but admitted being unproductive in their allocation of time and energy.

Finally, collegial relations were the most salient and pervasive source of dissatisfaction. New faculty did not find 
the stimulating conversation, mentoring and support they had hoped for; although $70 \%$ judged their department chair as good or excellent.

In a three-year study at a large, research-oriented state university, Boice (cited in Fink, 1990) posed and answered four questions about new faculty. First, do initial teaching patterns, adaptive or maladaptive, tend to persist? Boice found that over a two-year period though teachers received poor student evaluations and admitted not feeling good about their teaching styles, these same teachers continued to use ineffectual teaching methods.

Second, can anything be learned from the experiences of new faculty who mastered teaching quickly and enjoyably? The answer is that these people tended to have a positive attitude toward students, low levels of complaining about their campuses, actively sought help on teaching, had moderate levels of lecture preparation time, had more time for research and writing and participated in campus-sponsored faculty development programs.

The third question asked by Boice was how does success in teaching correspond to prowess in other areas, including collegial support and scholarly productivity? He found that there was a positive correlation, in that successful new faculty quickly established good relationships with colleagues and had more time to devote to research. 
The final question asked, how do initial teaching experiences compare at a "teaching" and at a "research" campus? Boice found little difference in experiences when examining interest in teaching, time spent with students outside of class and efforts to improve teaching.

Based on the results of this study, Boice recommended first that universities might consider not formally evaluating faculty for the first one or two years. He felt that this might encourage more creative teaching. Finally, Boice recommended that faculty development programs should aid new faculty by helping them reduce their overpreparation for lectures, help them find ways to increase student participation in class and help them to get their research programs going.

Before moving into an examination of the community college system, its nature, students, and faculty, a recap is in order. Thus far, several common concerns for both new secondary and new four-year faculty have emerged. One, the idea of mentoring, or pairing new instructors with experienced faculty members, was identified as a way to help the assimilation process. Two, both levels mentioned classroom concerns. On the secondary level, classroom management and student motivation were identified as newteacher challenges. At the four-year level university level, the idea of learning about the learning process and the basics of teaching was pinpointed as something needed by new 
Ph.D.'s. And finally, new instructors on both levels needed help learning about available resources and sources of support. It will be seen as the next section unfolds, that the new-teacher challenges described for secondary and university faculty will resurface in the following studies about community college faculty

\section{Community college Faculty}

This look at community college faculty is placed into groupings similar to those used in the previous sections. The rest of this section examines faculty diversity, the need for teacher preparation courses, and specific orientation programs. This chapter concludes with a description of workshops designed for new faculty at all levels of education. Before looking at specific studies about community college faculty, a brief look at the community college movement is necessary to provide a background knowledge about the nature of the institution and the faculty-oriented challenges generated by this nature. The community college Movement

A primitive, though some what still applicable definition of a community college is "An institution whose essential purpose is to serve the needs of its residents" (Reid, 1966, p. 112). Cohen and Brawer (1982) offered a more timely definition by stating that the commuity college is any institution accredited to award the associate in arts or science as its highest degree. 
The community college concept originated with missionaries and other religious clergy who brought their European educations and religious zeal to America. Many of the first colleges taught skills for agricultural and mechanical trades. Locally supported and governed, these institutions sought to serve local needs (Reid, 1966).

It is difficult to point to a single educational model as the one used exclusively by framers of the community college concept. Reid (1966) maintained that the first president of the University of Michigan, Henry Phillips Tappan, felt strongly that the German educational system was by far a superior educational model. The typical German university assumed no responsibility for the preparatory work done during the first two years of college. The German student entered the university only after completing the work of the "Gymnasium" at the end of the fourteenth grade. Thus, he was able to move immediately into advanced work in his area of specialization (Reid, 1966, pp. 85-86). Tappan called for universities to leave the training of the first two years of college to the high schools, in the form of "junior college work" (Palinchak, 1973, p. 41).

Lange articulated the relationship between the junior colleges and the university system (cited in Reid, 1966, p. 37). In a series of speeches and articles, Lange advocated democratizing the function of the junior college by making 
college education available to every high school graduate in the state.

Cohen and Brawer (1982) pointed to two social forces as significant contributors to the rapid expansion of the community coilege system--the need for workers trained to meet industry needs and the drive for social equality. In addition, the public believed schools to be avenues for solving societal ills and believed that more years of schooling were beneficial to the individual citizen. These factors combined to add fuel to the junior college fire.

Organized in 1920, a national association of junior colleges brought a new sense of professionalism to this developing educational sector (Reid, 1966). A few years later, in 1928, Cobb (cited in Reid, 1966) wrote that the junior college was an institution that could logically provide the opportunity for the transition of students from the unstructured instructional program found in progressive schools at the secondary level to work at the upper division level of the university (p. 41).

California community college Movement

Historians agree that the degree to which the junior college movement flourished in California is without comparison. In fact, according to Reid (1966) California became the reference point for discussion of the junior college system as a whole. Cohen and Brawer (1982) noted that although community colleges now operate in every state 
and enroll half the students who begin college in America, they found their most compatible climate in California. Cohen and Brawer also maintained that the introduction of the community college concept to the West was timely because during the eighteenth and nineteenth centuries religious and private colleges were strongly rooted elsewhere, but the west was yet unsettled. Therefore, it was much easier for the public college concept to grow and flourish with little competition from the private sector.

In 1907, California authorized the addition of two years of post-graduate education to existing secondary schools. Under this authorization, Fresno High School offered postgraduate classes in 1910, thus becoming California's first and the nation's second oldest public junior college in continuous operation (Palinchak, 1973, p. 79).

In 1960 the Master Plan for Higher Education was published. This treatise advised those responsible for the organization of higher education in California to identify the public junior college as an integral part of the system of higher education and to plan for its orderly expansion within the total framework (cited in Reid, 1966).

For a succinct and comprehensive look at the nature of today's community college as an institution, employer of faculty, and educational provider, see Cohen, 1971; Cohen, Lombardi, and Brawer, 1977; and Cohen and Brawer, 1977. Cohen and Brawer (1982) discussed a strong dichotomy of 
purpose faced by most community colleges. That is, is the function of the community/junior college to evaluate and determine likely candidates for the four-year schools; a purpose suggested by Tappan's German educational model discussed earlier in this chapter? Or, is it to assess and meet the educational needs of the surrounding community? Both are legitimate and important roles but each dictates its own special needs and administrative focus. The answer is not easy to articulate and probably lies in a combination of the two focuses. The result is a two-year institution that by necessity attempts to meet a variety of student needs and ends up with a curriculum that resembles a smorgasbord rather than a coherent, educational plan (Cohen, 1982). The dichotomy of focus, just described, when coupled with the open-door policy of the community college creates a student body of staggering diversity. The next section will explore further the nature and extent of student diversity because it is this element, created by the nature of the community college, that presents the first challenge encountered by first-year faculty members.

\section{Student Diversity}

McCluskey (1974) wrote that the community college system attracts, "all who desire and need to learn, whatever that learning may be" (p. 22). Similarly, Doucette and VenturaMerkel (1991) observed that community colleges enroll students representing a wide range of ages, racial and ethnic 
groups, and educational backgrounds and skill levels.

Because of their open-door admissions policies, community colleges are committed to providing a range of programs and services to meet the needs of all constituents, including those underprepared to meet the challenges of the classroom or the work place (p. 21).

Palinchak (1973) wrote that students become involved with comrunity college programs for a multitude of reasons, only some of which are purely academic. Cross (1983) maintained that community colleges should conduct student needs assessments to aid administrators in their endeavor to improve service to the students enrolled.

Cross (1981) noted that most community colleges are a combination of four-year transfer classes, vocational training, and adult education courses. In an effort to understand adult learners, Cross examined two important questions: First, who participates in adult learning? and second, what motivates their participation?

To answer these questions, Cross consulted the National Center for Educational Statistics (NCES). An examination of the 1978 participation rates in organized instruction revealed that most adult learners were between the ages of 17 and 34; were white females with one to three years of college; and were employed with an annual family income of $\$ 25,000$ or more. To answer the second research question: What motivates their (adult learner) participation?, again 
the NCES was consulted. The acquisition of knowledge was held as the most important reason for participating in organized instruction, with personal fulfillment and personal goals coming in second and third, respectively. In 1988, this researcher surveyed 84 adult learners at a California Community college using the same questions as Cross. The results of this informal study are as follows: the typical adult learner was a white female 17 to 34 years of age, employed with one to three years of college and an annual income of $\$ 25,000$ or more. These findings are identical with those of Cross in 1981 .

The results of the informal study with regard to question two were: $67 \%$ of the respondents indicated that they wanted to become better informed and $43 \%$ wanted to satisfy curiosity about the subject matter. The next most important reason for attending this community college was to satisfy personal goals, and the final reason was to enhance personal fulfillment. Again, these findings correlate to those determined by Cross (1981).

The community college, with its open-door admissions policy and community-based educational mission, attracts a large diversity of students. As a result, community college instructors face classrooms comprised of adult learners with differing individual expectations and needs. To meet the needs of all students is challenging, especially for the new instructor. The next section examines studies done about 
full-time, community college faculty. These studies range from demographic portraits to descriptions of workshops designed for the first-year instructor. Community college Full-Time Faculty

Part-time faculty (those who teach $40 \%$ or $60 \%$ of a fulltime teaching load) play a significant part in the community college system (see Yarger, 1982). However, because this study focuses on full-time faculty, this section of the literature review is limited to a discussion of full-time instructors.

Eaculty diversity and attitudes. Eckert and Williams (1972) studied 1,383 instructors from 43 community colleges and universities in Minnesota and compared the data for the various institutions. The results of the data comparison showed that four-year, public institution instructors were primarily male, born out of state, had earned Ph.D.'s and were concerned with their research opportunities. Four-year, private institution instructors were mostly male, born out of state, had earned Ph.D.'s and were greatly concerned with their relationships with colleagues. Public junior college instructors were mainly male, born in the state, had earned M.A.'s, and were most concerned with the age and type of students they taught. Finally, private junior college instructors were primarily female, born in the state, had earned M.A.'s and were most concerned with the kinds of students they dealt with. 
Also in the $1970^{\circ} s$, Patterson (1971) studied Pennsylvania community college faculty to determine the relationship between previous career experiences and attitude toward educational issues. He contended that a clearer understanding of attitudes of faculty with various career experiences is needed if community colleges are to be successful in helping faculty members put their objectives, philosophies, and programs into practice. His primary conclusion from the data gathered was that faculty who had not held previous assignments were more progressive than faculty who had worked in a public school, a junior college, a four-year university, business or industry.

Yarger (1982) examined the expectations of new part and full-time community college faculty. In his study, he asked 145 new teachers to respond to the same quantitative instrument before and after the first term of teaching. The instrument provided information on their perceptions of the importance of 10 basic teaching competencies for successful teaching. They were also asked about their perceived effectiveness in those same 10 areas. Finally, they were asked about the likelihood of their choosing to participate in orientation and early in-service activities when given five different sets of circumstances.

Yarger found that respondents held unrealistic expectations as they entered community college teaching; that is, they were less effective than they anticipated. He also 
found that part-time faculty were less likely to choose to be involved in organized instructional-development activities. Finally, Yarger's study revealed that almost all respondents supported the required orientation and early instructionaldevelopment activities, although they were less likely to involve themselves voluntarily in these activities.

Keim (1989) presented a research update about community college faculty. Her analysis was based on completed questionnaires from faculty from 51 colleges in 32 states. For reporting purposes, responses were grouped into the categories of: full-time instructors teaching transfer classes (148 respondents), and full-time instructors teaching occupational/technical classes (140 respondents). Keim found that most faculty were middle-aged and Caucasian. The highest degree earned by most faculty was the master's degree. In terms of teaching experience, the full-time faculty teaching transfer classes had a mean teaching experience of 14 years and full-time faculty teaching occupational/technical classes, 10 years.

Most participants belonged to national professional associations, but few participated in publication activities. The long range career goals of most full-time faculty were to remain in their current positions.

The preferred teaching style of the respondents varied between those who taught transfer classes and those who taught occupational/technical classes. Most faculty teaching 
transfer classes preferred a lecture and discussion style, while faculty teaching occupational/technical classes selected the "other" category that was not described in the report. Most respondents considered themselves to be effective instructors, but few had completed a formal course on the community/ junior college. Many faculty members were previously students at a two-year college and most respondents were satisfied with their present assignment. Wisniewski (1990) discussed the results of several surveys done by the Education Department's National Center for Educational Statistics. The report focused on faculty from the fall semester of 1987 and included data about compensation, workload, job satisfaction, future plans, and faculty characteristics, such as age, race, highest degree held, and tenure status.

The report maintained that the average university professor was a 47 year-old white male, who earned about $\$ 49,000$ a year and spent 46 hours a week on the job. The average commity college faculty member was also a 47 yearold male who earned about $\$ 38,000$ a year and spent 40 hours a week at work. In spite of a significant difference in salary, full-time community college faculty were the most likely of all faculty analyzed to be satisfied on issues such as collegial relationships, overall job satisfaction, workload, their institution's mission or philosophy, departmental and faculty leadership and salary. 
The previous section provided insight into some demographic traits and attitudes of full-time community college faculty. The next section will examine a common theme that has woven its way through the literature about secondary school teachers and four-year university faculty-the need for teacher preparation courses. New-Teacher Preparation

Over 40 years ago Koos (1950) suggested the need for a succinct presentation of the philosophy and focus of the junior college. He maintained that fewer than one in ten junior college teachers had an introduction to the junior college and its aims and purposes before starting to teach.

Such an introduction to the junior college system was written by Thornton (1960). He contended that, "Adequate preparation of these new instructors is one of the most pressing of our educational needs" (p. V). Designed to be a textbook for graduate students, teachers and administrators of community colleges, the study included a look at the background, organization, and operation of the community/ junior college.

McClure (1970) pointed to the need for colleges and universities to develop programs to prepare junior college teachers for the open-door nature of the junior college. His study centered on a survey administered to 34 oklahoma junior college administrators. The results of the study verified the 
need for special programs that addressed the unique philosophies and problems associated with the junior college. The diverse nature of community college faculty is also documented by Medsker and Tillery (1971). They contended that a large portion of faculty members are new to the community college institution. Thus, not only will they be unfamiliar with the culture of the institution but with the focus of the system as well. They reported that the highest percentage of new faculty are recruited from the public school system, the next largest group directly from graduate school, the next from four-year institutions, and the last largest group from business and industry (p. 89). In addition, only a slight percentage of community college instructors have been students in a community college or have completed courses dealing specifically with the community college system.

Matching new teachers with experienced, master teachers was advocated by Collins (1971). Collins maintained that community colleges needed more master teachers to handle highrisk students. He identified the lack of master teachers to the inadequacy of pre-service and in-service training. Collins stated that a month of intensive pre-service training was essential for all new faculty. This month was to be followed with an in-service training internship with a master teacher. The result of this combination, in his opinion, was a metamorphosis into quality teaching. 
Bleyer (1979) supported the ideas presented by Collins. She contended that teaching is the primary function of the community college and that there is evidence of a lack of and a need for effective programs of preparation for community college teachers (p. 46). Bleyer wrote that there is a need for orientation to be complemented by a well planned, integrated in-service program of faculty development. She recommended that prospective teachers have a Master of Arts in College Teaching or the Doctorate of Arts in Teaching (p. 48). In response to Bleyer's article, Smith (1981) also supported the need for pre-service programs and added that the job of the community college instructor is further complicated by the make-up of the student body. That is, community college admission policy insures several levels of scholastic ability often within a single classroom. Instructors need the understanding and skills to adapt instruction to a variety of ability levels. Smith responded to Bleyer's concerns by describing a support minor for the master's degree, offered through Southwest Texas State University. The minor is designed to meet the learning needs of those students desiring to join the faculty of a two-year college. Smith contended that graduates have a broader background of training in adult learning theory and teaching strategies and thus are better community college teachers.

Finally, Collins and Case (cited in Yarger, 1982) addressed the gap between subject matter competency and 
effective teaching by pointing to student diversity, curriculum diversity, and high classroom attrition rates as specific challenges faced by a community college instructor.

The need for teacher preparation courses for community college instructors is voiced by many researchers. Is it possible to address some of these issues in new-faculty orientation sessions? The next section looks at research focused on orienting new instructors to the community college and programs designed specifically for new faculty. New-Faculty Orientation

Collins (1971) discussed the use of master teachers as role models and sources of support for new teachers. Kelly and Connolly (1970) offered a similar model of new-faculty orientation. They stressed that incumbent faculty should be used as an integral part of the process they wrote that experienced faculty are often the most effective socializers to the system.

Lombardi (1974) included new faculty orientation as one of the many duties of the department/division chairperson. He explained that in the department new instructors get a more intensive informal indoctrination than they would normally receive from the formal orientation conducted by most colleges.

Silverman (1985) outlined a five-year staff development plan adopted by Santa Monica College; a portion of which was devoted to new-faculty orientation and a mentor program. 
Silverman described the orientation program as strong, innovative and a source of on-going support for new faculty. Conducted over a two-day period, orientation begins with a full day of presentations covering the major governance areas of the college. These areas include: the instructional program, admissions and records, personnel policies, instructional services, student services, and faculty organizations. In addition, a handbook is given to new faculty to supplement the presentations. The second day of orientation involves assigning each new faculty member a mentor for the coming year. Mentors are experienced faculty who have served as Academic Senate presidents. Mentors are assigned up to four new instructors and are expected to initiate their charges to the community college setting. Miami-Dade Community College District is often cited as having a strong staff development and orientation program. Roueche (1989) recommended that community colleges build orientation programs for all new faculty and staff to acquaint and educate them around the norms and values of community colleges. He pointed to Miami-Dade as a strong model for all community colleges and particularly supported the requirement that all new faculty and staff members must complete two graduate courses offered for credit by the University of Miami. These courses are taught in conjunction with Miami-Dade Community College, and the curriculum was collaboratively developed. Completion of these two courses 
is a condition of employment and an effort by the college to make sure that all new hires are properly socialized and trained to perform well in the unique setting of the opendoor college.

Roueche explained that Miami-Dade's program consisted of several components, some of which continued through the entire academic year. Orientation began with a five-day pre-service program that included information about the college, campus and department, the teaching/learning environment and departmental expectations of faculty. This segment was followed by monthly meetings designed to introduce incrementally new information about college services and the teaching/learning process. Monthly meetings continued through the first two major terms of employment. Finally, faculty mentors were assigned to new faculty and this source of dayto-day support continued through the initial calendar year of employment. In addition, new faculty were invited to participate in additional staff development activities. New-Faculty Workshops

This review of related literature has revealed several concerns that seem apropos to all levels of education: effective classroom teaching, use of mentors as a part of induction, and orientation to the nature of the employing institution. Eison and Hill (1990) outlined several workshops designed to meet the needs of new faculty at all 
levels of education, and the final part of this literature review will take a more detailed look at these workshops.

In a recent study by Eison and Hill, 69 college administrators, charged with the task of faculty development, responded to a survey about campus-based programs currently offered for new faculty. The research instrument requested information about successes, failures and aspirations for the development of new programs. Data analysis revealed that three types of programs for new faculty were identified and three sets of obstacles were described. The report concluded by listing 29 specific suggestions, grouped into eight categories, for the design of successful programs.

The researchers found that of the 69 schools that returned completed surveys, $90 \%$ reported providing a special workshop or program for new faculty. But, most of the programs were not mandatory for new faculty. Most programs were held prior to the start of classes, with the remainder "evenly distributed between programs offered during the first two weeks of the semester and programs offered during the third and fourth weeks" (p. 225).

After analyzing the data, the research team concluded that workshops for new faculty took many different shapes and sizes. In an attempt to pull together common data and to describe in a practical way the types of workshops offered, Eison and Hill developed labels for three types of programs, 
each of which fell under the ambiguous category of newfaculty workshops.

The first type of workshop was a "Campus Orientation Program." This workshop focused on the immediate needs of new faculty. The authors suggested that an effective campus orientation program could be accomplished in about a day and should be held the week immediately prior to the start of classes. Discussion topics could include: parking stickers, health and other insurance benefits, payroll options and dates for receipt of checks, photocopying policies and procedures applicable copyright restrictions, and secretarial services. In addition, an orientation program of this type could include an introduction to promotion and tenure policies and an introduction to teaching support services (pp. 226-7) .

The second type of workshop was labeled "Brief Teaching Effectiveness Workshop (TEW)." The Brief TEW could last up to two days and would be held immediately prior to classes. An important goal of this workshop was building a sense of community among new faculty members. Other goals could include an introduction to the institution's mission; administrative structure, procedures, and people; students and students' concerns. Finally, the development of a mentoring program for new faculty was encouraged (p. 227).

The final workshop discussed in the study was the "Extended Teaching Effectiveness Workshop." The Extended TEW 
lasted up to one week and was best held the week immediately prior to the start of the fall semester with follow-up sessions scheduled throughout the year. One tool of the Extended TEW was the use of small group assignments. Besides building a sense of community among newly hired faculty members, the small groups fostered insights into other disciplines. Topics discussed in this type of workshop included: strategies for evaluating teaching effectiveness; syllabus design; testing and grading; campus-wide projects related to instruction; discussion and modeling of different teaching styles; utilization of micro-teaching exercises and critique in a group setting (p. 228).

One part of the survey asked respondents to identify obstacles to the implementation of ideal teaching effectiveness workshops. Eison and Hill grouped these barriers into three types; the first of which focused on a lack of funding, institutional commitment, time, and staffing. The second type of obstacle addressed the fact that good teaching is not recognized or rewarded significantly. The final barrier was reported by one-third of the respondents and looked at various attitudinal problems like: "a sense that a new faculty member arrives all ready to go and needs little support; too many faculty still believe that knowing a subject means being able to teach it well; and established tradition that assumes that an all-day 
marathon orientation program is an efficient way to initiate new faculty to the institution" (p. 230).

The final section of Eison and Hill's report outlined suggestions for effective planning of new-faculty workshops. These suggestions included: gaining initial support for the concept, designing a new-faculty workshop, funding the program, staffing the program, communicating with participants, providing incentives to participants, presenting the program, and other important issues and considerations.

Evidently, there is a growing awareness of the special support needed by new faculty. This dissertation accomplishes the next logical step. That is, new faculty members are asked to voice the challenges they encountered, the support they received and describe advice they have for helping the institution meet the needs of first-year teachers. This information will help not only college administrators, but anyone interested in aiding a new instructor.

\section{Summary}

This review of literature has examined three segments of education to draw out themes pertinent to new faculty members. At the secondary level, concerns like classroom management, identifying and using support resources, motivating students and establishing positive relationships with other teachers and administrators were expressed. 
At the four-year level the research revealed that until recently, new-teacher orientation meant orientation to the institution and was usually done by the department chairperson or by senior faculty members. However, current research identifies the need to bridge the gap between subject matter expertise and effective teaching. This concern did not emerge in the secondary school literature probably because these teachers have as a part of their degree curriculum teaching methods courses and practicums. Finally, this chapter focused on several aspects of the community college: It revealed that the two-year college is perhaps the most rapidly growing segment of education. In addition, the nature of the community college is such that there is a dichotomy of purpose that interacts to produce a varied and diverse student body. This observation when coupled with the open-door policy of admissions results in a multi-faceted set of challenges for new faculty. The literature pointed to the diversity of the student body as a fact of life that dictates that an instructor often must teach to the median competency of the class. Two-year college teachers, like four-year college teachers, are not likely to have a background in teaching methods, a helpful tool when facing a community college classroom. In addition, many new community college instructors are not familiar with the nature of the community college as an institution and are unprepared for the multi-cultural and community pressures 
that often influence college operations. In an attempt to address these well-documented challenges, several pre-service and in-service workshops were described in the last part of this chapter.

This chapter has laid the theoretic groundwork for the dissertation study described in the next three chapters. There is an on-going need for research about community college faculty. The next chapter describes the methodology used by this researcher as she explored the challenges experienced by first-year community college instructors. 


\section{CHAPTER THRET}

Research Design and Methodology

Introduction

In Chapter Two, the review of literature contained several studies that described community college faculty and reviewed programs for new faculty. For the most part, these studies were either statistical, demographic profiles of community college teachers or studies that described community college orientation processes and procedures. The scope of these studies was such that they reported data about the community college culture or world, but did not look deeper into the "why's." That is, why do some professionals choose community college teaching instead of other sectors of education? Why do instructional administrators include what they do in orientation programs? There is a continuing need for research that looks to answer the "why's." Research of this type delves into the cultural and political context in which statistical studies are conducted. The qualitative research done in this dissertation study provides an in-depth look at a slice of community college context and culture. Thus, it is a phenomenological study that seeks to uncover a phenomenon experienced only by newly hired, full-time, 
community college faculty--the challenges experienced during the first year of hire.

Tesch (1984) described phenomenological research as descriptive research that deals with the inner experiences of individuals (p. 25). He also noted that this type of research considers participants in the study to be the true experts in the experience; in essence, the co-researchers. Studies of the phenomenon are typically conducted in an interview format where participants share their expertise and engage in intense reflection about their experiences (Tesch, p. 29) .

Marshall (1984) wrote that "Qualitative research has unique qualities for exploration. A 'goodness' that allows researchers to explore and generate hypotheses" (p. 1). In addition, she maintained that researchers must match research methods with research questions and the choice of qualitative methods is appropriate for some fundamental questions about education. The research questions guiding this study are phenomenological in nature. They ask participants to describe the first-year experience in order to provide answers to fundamental questions. For example, why is the first year of hire usually a challenging time for new instructors? What are some common challenges? What seems to cause the challenges? What can interested parties do to help new faculty deal with these challenges? These questions go beyond demographic portraits and program descriptions and 
explore an important phenomenon experienced only by new instructors. The remainder of this chapter reviews validity issues, the sites used in the study, the population used, the instrument used to gather data, and the method used to analyze the data.

Validity Issues

The research findings presented in this dissertation are drawn from a study using a naturalistic design. That is, the study emphasizes a natural setting for data collection. An example of a study that does not use a naturalistic design is a pen and pencil survey. According to Borg and Gall (1983) solid internal validity is as important in the naturalistic design as it is in the experimental design.

one way to strengthen internal validity is to use a random sample of the defined populous. In this study, the entire defined populous at Sites 2 and 3 were included in the study. At Site I almost half the defined populous were included using a random selection, shuffled deck method.

Another way to strengthen the reliability aspect of internal validity is to field test the interview questions. The questions used to collect data for this study were left unchanged based on the success of the field test interviews.

A final way to strengthen internal validity is in the researcher herself. In the naturalistic design, the researcher is the primary study instrument. Therefore, preconceived notions about the phenomenon must be identified 
and set aside. Tesch (1984) noted that the researcher must proceed with the "highest degree of open-mindedness of which one is capable, to let 'the things speak for themselves'" ( $p$. 28). Similarly, Peshkin (1988) maintained that researchers should begin with the premise that subjectivity is inevitable. He recommended that researchers actively seek out their subjectivity during the research process so that subjectivity does not shape the inquiry and its outcome.

Because this researcher has never been a member of the study populous, it is easier for her to identify presuppositions and to keep them from influencing the phenomenon exploration.

\section{Data collection Sites}

Data collection sites include three schools of different sizes. The faculty and enrollment figures presented for each site are from Fall 1989. The new-faculty orientation described for each site if descriptive of the program attended by participants during their year of hire. It is possible that current programs at the three sites are now different. Finally, it should be noted that all sites are fully accredited by the Western Association of Schools and Colleges. A more detailed description of each site follows. Site 1

Site 1 describes itself as an urban-center college. Founded in 1914, it is one of three community colleges making-up a multi-school district. Situated on a 56 acre 
campus, Site 1 has 13,000 full and part-time students and employs 150 full-time faculty.

Orientation for new faculty is held in the fall semester and is broken into six three-hour sessions. The first five sessions are held Friday afternoons and address topics such as orientation to the college, exploring diversity at the college, getting to know the human resources at the college, and innovation and change at the college. The final session is a "celebration" held at the college president's home. Site 2

Site 2 was founded in 1946 and is a single-college district. Besides the main campus, there are also several education centers within the 2,500 square mile district boundaries. The main campus and ecucation centers serve 19,000 full and part-time students and employ 260 full-time faculty.

New-faculty orientation at Site 2 is handled at the department level. New-hires attend an eight-hour orientation to the college designed to welcome all returning staff and faculty. During afternoon break-out sessions, new faculty meet with the department chairperson and other department colleagues.

\section{Site 3}

Founded in 1934, Site 3 is a single-college district with two campuses. The main campus is on 168 acres and serves 5,600 full and part-time students. In 1988, the district 
opened a second campus which serves about 2,400 full and part-time students. The district employs 100 full-time faculty members.

New-faculty orientation occurs before the fall semester orientation session that includes all returning faculty and staff. The program for new instructors is an eight-hour block that includes: introduction of instructional administrators, description of the academic senate, introduction to tutoring services and student services, introduction to personnel staff and the Learning Resource Center staff and an explanation of the new-hire evaluation process.

\section{Repulation}

The Human Resource departments at all three sites provided this researcher with participant names. Nineteen participants, from the three community colleges described above, took part in the study. All participants were hired in the Fall of 1989, and are full-time, tenure-track, teaching faculty. Prospective interviewees were contacted by telephone and invited to participate. Appendix A outlines the format for initial telephone contact. A copy of the interview questions was sent to participants who requested them (see Appendix $C$ for thematic interview guide). Each member of the subject population was interviewed once with interview times averaging about forty-five minutes. 
Although there were no anticipated risks to participants, in each interview, the following risk management procedures were used.

\section{Risk Management Procedures}

1. Each participant read and signed a consent form (Appendix B) immediately prior to the interview.

2. Each participant was reminded that the interview would be audiotaped to aid with data analysis, but that the tape would be erased immediately after the dissertation study was accepted.

3. Each participant was reminded that interview results would be reported in aggregate form and that the employing school would not be named in the study. If a direct quotation from the interview was used in the study report, the interviewee would be referred to as "participant" or "respondent" to protect anonymity.

4. Each participant was reminded that he or she could choose to end the interview at any point.

5. Each participant was given an explanation of the research project and the opportunity to ask questions immediately prior to the interview. Participant Selection

Site 1, hired 17 tenure-track instructors in the Fall of 1989. A random, shuffled deck method was used to select potential participants (Mason and Bramble, 1989, p. 116). This method involved placing the individual names of the 
seventeen potential members on single cards. After shuffling the cards, names were drawn in random order. Based on the random draw, the researcher compiled an ordered list of names from one to seventeen. Beginning with number one, the researcher contacted prospective interviewees by telephone and invited them to participate. The researcher continued down the ordered contact list until eight instructors had agreed to participate.

At Site 2 six instructors met eligibility requirements. Five participated in the study, one instructor declined because of time constraints.

Site 3 hired eight instructors in the Fall of 1989. All eight were contacted and six accepted. Two instructors declined because of time constraints.

\section{Instrument}

In line with the recommended method to examine a phenomenon, data were gathered through interviews ( Tesch, 1984). The researcher field tested interview questions in an attempt to identify potential problem areas, utilizing a community college not used in the research study. Two faculty members, hired in the Fall of 1989, were interviewed. The field test revealed no significant problems and the interview questions remained the same.

Research questions were explored and answered via the interview questions. Beyond the frame provided by the research focus, the interview questions remained open-ended. 
To this end, emergent experiential themes were addressed as they surfaced in each interview.

The researcher audiotaped interviews to free her from the task of on-the-spot transcription of interview responses. Audiotapes are a valuable tool in data analysis because the researcher can listen to the interview session as often as is necessary to identify experiential themes. In addition, direct quotations can be transcribed from the audiotape to add clarity and emphasis to the data analysis.

\section{Data Analysis}

Phenomenological research deals with individual perceptions. Marshall (1984) described two separate strands of qualitative research. The first tests hypotheses in context, in the field, using many sites to identify the range and intermixing variables. This strand seeks to build current knowledge and improve current practice. The second strand explores "without knowing what theory will explain phenomena, without assuming a particular world view or hierarchy of needs and interpretations" (p. 10). The research done in this dissertation study incorporates both strands as described by Marshall. For example, the study used three community college sites to identify challenges, sources of support and to identify the important variables that come into play during the first year of hire. This research seeks to discover the challenges and sources of support as reported by new instructors. As a result of the 
data collected, common themes are identified and conclusions are drawn. The intent, then, is to build current knowledge and to improve current practices with regard to new faculty. Marshall's second strand stands out in this study because the research did not seek to replicate a past study, but to explore without any particular world view in mind.

The data from this phenomenological study were analyzed according to the guidelines provided by Hyener (1982). Hyener suggested that datum is reviewed and reduced down until the researcher gets at the phenomenon of interest. During data analysis, the researcher compiled copious written notes that documented the progression of data into units of meaning, and eventually themes. Before the audiotaped data were analyzed, participants were each assigned a number ranging from one to 19 . During the analysis, participants were identified only by their assigned number; that is, names were not included on the researcher notes. Interviewees at Site 1 were numbered one to eight. Site 2 had numbers nine through 13, and site $3^{\prime}$ s interviewees were numbered 14 through 19.

The first step in the analysis process was to listen to each participant's taped interview and record all responses. Responses were recorded on a sheet of paper with the interview question and the participant number clearly identified at the top of the paper. This process was repeated until the answers of all 19 participants had been 
recorded and categorized according to each interview question.

The next step was to take each interview question in turn, and compare the individual answers of the participants. The 19 sets of answers for each interview question were examined for similar responses. Similar responses were grouped together until themes emerged. For example, some respondents stated that within a single classroom there is often a wide range of student skill-levels. Other respondents related that there were varying degrees of student abilities present within a single classroom. During analysis, these responses were grouped together because they addressed the lack of homogeneity within the community college classroom. The theme assigned to these responses by the researcher was "student diversity." In Chapter Four, tables show how similar responses are grouped. In the case of "student diversity" the table is labeled "Student Diversity Challenges." Also provided for the reader (within the table) are the itemized responses that comprise the theme and the frequency for each response given.

\section{Summary}

This chapter explored the research design and methodologies used to carry out this study. It described validity issues, the data collection sites, the target population, the research instrument, and the data analysis 
method. This chapter presented the components used to collect the data presented in the next chapter. 


\section{CHAPTER FOUR}

\section{Findings \\ Introduction}

The nature of this study is descriptive. Its intent is to study the phenomenological experiences of first-year community college teachers. Specifically, the study examines that portion of the phenomenon that encompasses the problems and sources of support encountered by new faculty during the first year of hire. In line with the methodology recommended to examine a phenomenon, an interview methodology was used to gather data. The researcher analyzed responses from the audiotaped interviews and from the comments themes were generated. The researcher, at her discretion, grouped similar responses into themes and formed these themes into frequency response tables. When a single distinctive response was given that did not accurately fit into any of the themes indicated by other participants, that response was listed with a frequency of one indicated. Respondents were free to indicate more than one answer to a single question. Tables are used to report response frequency counts in order to present a clear picture of the amount of respondents choosing a specific category. Within each table, responses and themes are summarized in rank order according to the 
number of responses in each category. Each table indicates when multiple responses are given. The tables developed are supplemented with a narrative explaining the themes identified by participants. Quotes are used to provide clarity and emphasis. This chapter organizes its presentation of data according to the order of interview questions, as asked of the participants. Following the discussion of data drawn from each interview question, the research questions are reexamined and answered.

\section{Respense Rates}

Thirty-four instructors qualified as participants in this study. By site, the break down is as follows: Site 1, 17 instructors were hired in the Fall of 1989 on a tenure-track basis. The researcher selected eight using a random, shuffled deck method. At Site 2, six instructors were hired in the Fall of 1989 and five participated in the study; one instructor declined because of time constraints. At site 3, eight instructors were hired in the Fall of 1989 and six participated in the study; two instructors declined because of time constraints.

\section{Interview Question one}

Tell me about your previous teaching experience. Table 1 combines the data from all three sites and presents a composite picture of participant teaching experience. It is not surprising that most new instructors hired had previous community college experience. Only one 
participant had worked previously on a full-time basis for a community college. Most new hires with part-time community college experience had taught for the employing institution. of those hired with no community college teaching experience, four had worked at private and public universities on a fulltime basis, and only one new hire came straight from graduate school where she was a teaching graduate assistant.

Table 1

Rarticipant Teaching Experience

\begin{tabular}{|c|c|c|}
\hline $\mathrm{N}=19$ & $\mathrm{~N}$ & $\%$ of $\mathrm{N}$ \\
\hline \multicolumn{3}{|l|}{$\begin{array}{l}\text { Previous Community. } \\
\text { college. Teaching Experience }\end{array}$} \\
\hline Full-Time at Community College & 1 & \\
\hline Part-Time at Site & 8 & \\
\hline Part-Time not at Site & 5 & \\
\hline Total & 14 & 748 \\
\hline \multicolumn{3}{|l|}{ No Previous community } \\
\hline \multicolumn{3}{|l|}{ cellege Teaching Experience } \\
\hline Full-Time Teaching Public/Private & 4 & \\
\hline Part-Time or Teaching Assistant & 1 & \\
\hline Total & 5 & 268 \\
\hline
\end{tabular}

To explore the data in another way, Table 2 summarizes the teaching background of each participant by site. 
Site 1 , the urban-centered, multi-college district, contributed eight participants to this study. This site had the highest number of new hires with no community college experience. All three who fell into this category taught on a full-time basis at public and private institutions. Also at Site 1, the remaining five participants were teaching for the college on a part-time basis until hired on full-time.

Site 2 , is a single-college district who contributed five participants to this study. Only one new-hire had no previous community college teaching experience. The remaining four new instructors all had earlier part-time experience with a community college, and of those four, three had taught at the employing institution.

Site 3, a small, single-college district contributed six participants to this study. Of those six, one person had no previous community college teaching experience. The remaining five participants all had previous community college teaching experience, one in a full-time position and the other four as part-time instructors. This site did not employ any part-time instructors who had previously held adjunct positions at the institution.

The data gathered by interview question one presented an overview of participant teaching experience. This information is reexamined in research question three in discussing whether there is a relationship between the amount 
and type of previous teaching experience and the kinds of challenges experienced the first year of hire.

Table 2

Participant Teaching Experience Presented by Site

\begin{tabular}{|c|c|c|c|c|}
\hline & & \multicolumn{3}{|c|}{$\mathrm{N}$} \\
\hline & & $\begin{array}{c}\text { Site } 1 \\
\mathrm{~N}=8 \\
\end{array}$ & $\begin{array}{c}\text { Site } 2 \\
\mathrm{~N}=5\end{array}$ & $\begin{array}{c}\text { Site } 3 \\
N=6\end{array}$ \\
\hline \multicolumn{5}{|l|}{ Previous Community } \\
\hline $\begin{array}{l}\text { Full-Time at } \\
\text { Community College }\end{array}$ & 1 & 0 & 0 & 1 \\
\hline Part-Time at Site & 8 & 5 & 3 & 0 \\
\hline Part-Time not at Site & 5 & 0 & 1 & 4 \\
\hline Tota 1 & 14 & 5 & 4 & 5 \\
\hline \multicolumn{5}{|l|}{$\begin{array}{l}\text { No Community college } \\
\text { Teaching Experience }\end{array}$} \\
\hline $\begin{array}{l}\text { Full-Time Teaching } \\
\text { Public/Private }\end{array}$ & 4 & 3 & 1 & 0 \\
\hline $\begin{array}{l}\text { Part-Time or Teaching } \\
\text { Assistant }\end{array}$ & 1 & 0 & 0 & 1 \\
\hline Total & 5 & 3 & 1 & 1 \\
\hline
\end{tabular}

Interview Ouestion Two

Think about the challenges you experienced this past year. I'm going to mention some categories and I'd like you 
to describe the challenges or problems you encountered with each area:
a. Students
b. Teaching load
c. Collegial relationships
d. Administration or college governance
e. Faculty organizations

Are there any other areas that presented challenges that you would like to add to this list?

\section{Students}

Nine out of 19 respondents cited student diversity as the biggest challenge of this category. The term "diversity" is used by this researcher to encompass a number of studentrelated challenges. These challenges include: student reasons/motivation for participation, quality of day and night students, student skill levels, student ethnic diversity. Table 3 summarizes the responses.

Ne problem. Although the relationship between teaching experience and student-related problems is explored later in research question three, it is interesting that the nine respondents who stated that they did not experience problems with students also qualified their responses by pointing to previous experience with the community college system.

Student reasons / motivation for participation. Five instructors stated that it is challenging to meet the needs of all students electing to take a particular class. Most 
Table 3

Student Diversity Challenges

\begin{tabular}{ll}
\hline Challenge Area & $\mathrm{N}^{*}$ \\
\hline No Problem & 9 \\
Reasons for Participation & 5 \\
Day vs. Night Students & 4 \\
Skill Levels & 3 \\
Ethnic Diversity & 1
\end{tabular}

*Note: Multiple Responses Given

classes are comprised of students with distinctly different reasons for enrolling in a course. For example, a single class may contain university students completing undergraduate requirements, two-year students seeking to build marketable job skills, and newly graduated high school students who, according to one respondent, are "trying to figure out if they belong in a community college." These diverse purposes for enrolling frequently result in a wide array of motivation and interest within the classroom. One respondent observed that:

The challenge is trying to come to a common denominator to deal with all the interest levels you have. The transfer student (photography major transferring to a university) is maybe more interested in the theory, the aesthetics. The two-year student (seeking an associate 
degree in photography) is interested in learning the technique and then some students don't want to be bothered with either one. They just want to get some information, enough to play around with and have fun. I think the challenge with the student is balancing that. You want to retain all of them. You don't want to scare any of them away. I guess you offer a little bit of each and still maintain the level of education you want to. Quality of day vs, night students. Four instructors found it challenging to adapt the same course material to meet the differing needs of day and night students. Night students were mentioned by three of the interviewees as being more "dedicated and involved in the educational process." One respondent found more behavioral problems in his night classes and attributed his observation to students coming to class under the influence of alcohol or drugs. It should be noted that most of the participants in this study teach only day classes. This could explain the small response number in this category.

Student skill levels. Three instructors pointed to the number of different skill levels, within a single classroom, as being a challenge. One interviewee related that:

The first thing that was very overwhelming was trying to accommodate a class full of students with wide-ranging skills. To try to make things not so fast-paced or over the heads of students who might be somewhat deficient 
right now in skills but yet maintain the interest of students who are obviously light years ahead of other people is a challenge.

Another interviewee stated that what she thought was skill deficiency with a student, turned out to be a learning disability. Although no other participants addressed learning disabilities as student challenges, it is difficult to say that challenges resulted from inadequate skill preparation and that are reflective of learning disabilities. The nature of the community college is such that both types of students could be found in a typical classroom. Perhaps this was the case that prompted one respondent to state: The first thing I noticed was the huge diversity, the incredibly broad diversity. From students who are brilliant to students who are absolutely lost day in and day out; they have no idea what's going on. You have to be much more flexible and I wasn't told that when I went to [teaching at] the community college. Student ethnic diversity. Ethnic diversity is the final type of student challenge cited, with only one interviewee mentioning it. The class taught by this instructor is an activity-type class and the instructor found that certain cultures do not like to be touched (as when correcting a dance posture) or criticized, even constructively, in front of other students. 
Teaching Load Challenges

Comments about teaching loads ranged from "too heavy" to "teaching at one school full-time is much easier than teaching the same amount of hours for three different schools. Table 4 summarizes the number of responses for each type of challenge.

Table 4

Teaching Ioad Challenges

\begin{tabular}{ll}
\hline \hline Challenge Area & $\mathrm{N} *$ \\
\hline \hline Too Heavy & 6 \\
Full-Time Easier to Manage & 4 \\
Manageable but Challenging & 3 \\
Reduced First Semester & 3 \\
Hours Awkwardly Arranged & 2 \\
No Problem & 1 \\
\hline
\end{tabular}

*Note: Multiple Responses Given

Load too heavy. Six participants felt that their teaching load the first year was too heavy and in some cases overwhelming. In one interview a respondent related that he taught three classes the first semester that he had never taught before. This situation generated a tremendous amount of preparation time and added stress. Another interviewee felt physically ill the first semester as a result of trying 
to adjust to moving his household to the area, learning the workings of the institution, and teaching a full load. Two participants used the word "overwhelming" to describe the teaching load that first semester.

Three respondents found themselves faced with the task of developing new instructional programs. These participants found the first semester extremely taxing. One of the interviewees asked his department chairperson for a reduced teaching load or some other sort of support in developing the new program, but his plea fell on deaf ears. In his words, "It sounded like I was complaining when I talked about it, so I just kind of stopped talking about it."

Eull-time load easier te manage. All respondents in this category previously taught on a part-time basis for more than one community college before being hired full-time. These three participants felt that teaching two or more part-time assignments at different institutions was more difficult than teaching approximately the same amount of hours in one place. In addition, three interviewees observed that they felt as if they were doing a better job teaching because they now had an office and office hours, thus increased student contact.

Load manageable but challenging. Three of the 19 interviewees stated that their teaching loads were challenging but manageable. Of these three interviewees, one respondent thought his load was "ok" but still was very busy getting used to the institution. Another participant found 
that she had to get organized and develop a realistic attitude about what she could accomplish at home (with regard to grading student assignments). The final observation included in this category came from a new instructor who found if difficult to adjust from a quarter to a semester system. The challenge for her was in adapting material to fit the longer time frame.

Teaching load reduced first semester. Although this category does not outline specific challenges, it is mentioned here because the three respondents with reduced teaching loads the first semester attributed the absence of problems to the first semester's reduction in teaching hours. Two participants were from the same department and found the policy to be especially helpful. As a result, both felt that they were significantly more effective the first semester with the classes they taught. The third respondent was involved with department administration, and was given a reduced load to off-set these additional responsibilities. Teaching hours awkwardly arranged. Two interviewees found their teaching schedules to be manageable but awkwardly arranged. According to one respondent, "The number of classes the first year was not difficult, but the way they were distributed across the schedule was. I was handed a very bad schedule. That whole semester I couldn't get enough sleep to function." Another interviewee found that the other, tenured, full-time faculty member took the prime 
teaching hours. This respondent was one of those cited earlier as having been saddled with the task of building a new program and felt the hours he had available to hold classes would not attract students to the program he was trying to build. As a result, both participants found it challenging to deal with the existing schedule they were assigned the first semester.

Collegial Relationship Challenges

Most respondents reported that there were no serious problems with collegial relationships the first year of hire. Most reported having a supportive dean, department chair and colleagues; but many qualified their responses with what they considered to be minor challenges. Table 5 illustrates the collegial relationship challenges mentioned by interviewees.

Table 5

Collegial Relationshis Challenges

\begin{tabular}{ll}
\hline Challenge Area & $N^{\star}$ \\
\hline \hline & 6 \\
No Problion (Physical and Emotional) & 5 \\
Relationships with & 3 \\
Department Members & 3 \\
Fitting into Department Structure & 2 \\
Responsibility to Department & 3 \\
\hline
\end{tabular}

*Note: Multiple Responses Given 
Iselation physical and emotional. Responses in this category included examples of both emotional and physical isolation with regard to colleagues. In one case, an instructor felt that she had to convince other college faculty of the legitimacy of her program:

The new person needs to convince the old faculty that your job is important and what you're doing is legitimate. When they don't have any prior background with you it's a little harder than if you've been around and worked with these people on committees and they like you and know you as a person; they're more willing to bend rules and help your students more. Another interviewee was new to the area and felt that the college did not put much effort into trying to help him adjust to the new school. He felt isolated because the tremendous struggle to adjust personally and professionally did not leave him much time to seek out and meet colleagues. Three of the respondents were put into offices that were physically removed from the their departments and this caused them to feel isolated physically, and emotionally out of touch with colleagues who could ease their assimilation in to the department. One respondent wanted to change a textbook and to this end approached an administrator who she thought was the appropriate person. She related her experience thusly: 
For me, the key within my department was finding out exactly who in my department was in charge of what. If you want to make a change, who do you go to first? Because I found out, the hard way, if you don't go to the right person first there's all kinds of trouble. Relationships with other department members. In this category, interviewees generally had no problem finding their "niche" in the department structure, but encountered individual challenges with specific colleagues. One instructor found that "they [department colleagues] were explaining to me each other's attitudes and never their own." This lead to a conflict situation where the new person often "stepped on toes" by not understanding her colleagues' personal agendas. A not-so-common problem was experienced by two participants in the form of hostility from part-time department members who did not get the full-time position. Although the aggression took a passive form, the respondents found it challenging to soothe a hostility that they had no part in creating.

Eitting inte the department structure. Three respondents found it challenging to fit into the existing department structure. In one extreme case the interviewee was hired to teach in a department that, according to her, "was stuck in their ways." She found it challenging to maintain her individuality as a 30 ish female, fresh out of graduate school while trying to mesh with a department of 50 ish males who 
were long-time faculty at the institution. Another interviewee stated that his primary concern was "to try the best I could to work in, in my proper place as the new guy on the totem pole." Similarly, the third respondent observed: There is seniority and you realize that your vote doesn't count for a whole lot. You don't want to create waves and when we have departmental meetings, I think my first year I probably never said a word. This year sometimes I'm brave enough to ask questions, but you really don't want to create too many waves. Respensibility to the department. Two interviewees commented on how their outlook on their department and colleagues changed as they moved from part-time to full-time. One instructor noted that: There's an interesting dynamic and this is probably one of the most noticeable things that came to me when I was hired full-time. That as a full-time instructor I now have not only more responsibility but let's say more input into the workings of the department. As a parttimer you have little to no input into class schedule, what classes you will teach, what time you will teach them, etc.

Similarly, another participant recalled that:

All of the sudden you're a part, and you never realized that you were not a part before. It was kind of an eyeopener for me because I was here so long. I always felt 
like I was a part of this department. Your relationships with fellow teachers takes on new meaning and you can talk with them differently. Administration or college Governance Challenges

This category prompted a number of varied types of responses. Responses have been grouped according to the nature of the problem addressed. Table 6 illustrates the frequency of responses given for each challenge area. Each category is discussed in more detail.

Rolitics. Seven respondents indicated that learning the politics of the college or their departments was a problem to be taken seriously, especially during the first year of hire. One participant was not willing to risk making political mistakes the first year when he was struggling to adjust to a new school. In his own words:

Basically, I was so overwhelmed with just adjusting--the move and the classes and the course load and stliff--that I made a conscious decision to not get involved in anything outside of the departmental affairs. Now, there was some pressure to get involved in the college governance but $I$, being a new member, felt wary because I didn't know the power structure and I wasn't about to jump into something when I already felt overloaded with work.

Another interviewee expressed the same reluctance to become involved in governance the first year of hire: 
There's no manual that tells you how things work. I mean, there's a faculty manual but it really doesn't give you specifics. There's a lot of mystery about how things run and how things work. What you really need to do to get things done; who you have to deal with. I guess you could call it politics. It's a mystery and it's a challenge, because I'm not really a political person. I like to go from $A$ to $B$ and not have to massage someone to get something.

Still another participant explained the challenge of uncovering the political networks of the institution as this: That first year you're not really sure who's who. I mean you really do sort of walk on eggshells you know. Who do you question? What do you say? How open can you really be in criticizing anything or asking questions? Becoming aware of how the employing institution was run was not always seen as a negative factor. To some, it was simply a step in fulfilling the terms of employment. One interviewee, who had previously taught on a part-time basis for the institution, felt the challenge was "getting used to having to work with the administration to get things done. I think it is a learning process, you have to see how it works." Finally, in this category, a respondent pointed out that learning about the institution was her biggest challenge the first year: 
The challenges of the first year are basically getting to know the institution you're a part of, and how the wheels work. The rules are laid out reasonably clearly [sic], but nonetheless you still have to be paying attention to them and figuring out how the process works. What's really important, where you need to focus your energies. It becomes a time management question as well as an energy management issue.

Shared governance. Seven respondents commented on the idea of shared governance, prompted by recent California legislation. Shared governance is a theory of college governance that involves faculty members in some of the decision-making aspects of administration. Some respondents felt that the time they took from teaching preparation to participate on committees was wasted because the committees were ineffectual. This was a problem because most new faculty had little time to waste. For example, one participant felt that "the administration is going to do what the administration is going to do regardless of what I think or what I want. I am on committees and I participate, but I can not really feel that I am a part of it." A similar view was expressed by an instructor who stated that "committees are full of power-mad people who want to keep things the way they are."

Most respondents appreciated the fact that their institutions did not require their participation during the 
first semester of hire. Those participants who did choose to join committees were given the option of choosing committees that were of personal interest to them or related to their field. According to interviewees, this option made committee work more personally fulfilling. Although during the first semester most new-faculty were discouraged from joining committees, some felt that it was expected of them if they were to have a good chance at obtaining tenure. Although these respondents were not unhappy with the time spent doing committee work, they did feel that it was challenging to fit it into a schedule already strained with the pressures of being a new faculty person.

Not everyone felt that committee work was wasted time. Five respondents indicated that being on a committee was a good way to meet other faculty members. One interviewee felt that not only was committee work a good way to get to know other faculty, but also a good way to begin to uncover the political agendas of other faculty members. She maintained that:

The challenge was figuring out how things operate; who these people are in relation to others. What has merit and what is a waste of time. All those things that rest in the minds of people who have been there for awhile, you have to go out and get a hold of. And the only access I know of is through committee involvement. 
Table 6

Administration or college Governance challenges

\begin{tabular}{ll}
\hline Challenge Area & $\mathrm{N} *$ \\
\hline \hline Politics & 7 \\
Shared Governance & 7 \\
Evaluation/Tenure Process & 4 \\
No Problem & 4 \\
Credibility with Administrators & 3 \\
Funding & 2 \\
\hline
\end{tabular}

*Note: Multiple Responses Given

Evaluation/tenure process. Although the teaching evaluation system was recognized by all respondents as being necessary, some found it challenging and stressful especially during the first semester of hire. Four respondents felt that either the process of evaluation affected their performance in the classroom or because the tenure process was not clearly explained, they needed to be particularly careful of not offending another faculty member. One participant, the only instructor with previous full-time teaching experience in the community college system, felt that the evaluation process was stressful even though she was quite confident with her teaching ability. In her words: It's very stressful when you're trying to learn the ropes and at the same time you've got four or five people 
coming into your classroom plus hours of meetings with them beforehand and afterward and then writing up your self-evaluation. It's a tension builder. Another participant voiced a similar viewpoint:

In your first semester of trying to learn the way a new college operates, as well as a very complicated evaluation process that the new instructor is responsible for putting together. And having all of the forms and all of the meetings and all of the arrangements for when people are going to evaluate them; was very unsettling. I honestly don't think I was as effective in my first semester as I was in my second.

In three cases, participants observed that they had to seek out their department chair to find out how the tenure system worked. This they found particularly disconcerting. The stress generated by not knowing the tenure process was articulated by one respondent:

I spent my first year more worried about offending people than anything else, because I didn't understand the tenure process. I was under the impression that all it took was one faculty member at a department meeting saying he thought I should not be rehired and I was out. credibility of the individual with administrators. The three participants who responded to this area reported similar kinds of credibility concerns. The first was credibility of the program she was hired to develop. She 
reported that the first year she felt under tremendous pressure to show administrators that student support for her program was growing each semester. She felt that increased student numbers showed administrators that her program was legitimate and that she was a credible educator. The other two interviewees found it challenging to build individual, professional credibility with their departments. In each of the two cases an outside consultant reviewed their departments and made a list of recommendations that were later incorporated. The changes adopted had been suggested previously by each of these new department members but not considered seriously by their department heads.

Funding. Two respondents referred to money as being a challenge the first year, but in two different ways. The first interviewee was frustrated with trying to get funding for her program. In her words, "Nobody wants to tell you about money--how do you go about getting funding? Politically, you don't want to do the wrong thing by asking. I was very cautious the first semester to not step on toes." The second respondent was concerned about large class sizes as a result of administration's need to gather as much $A D A$ (Average Daily Attendance--money received from the state to support instructional programs) money as was possible. Although he realized that dwindling funding from the state was a reality that needed to be managed, he stated that "I find myself wondering how much education the school is 
willing to sacrifice for the student load or ADA." It was his opinion that large class sizes exacerbated his struggle to adjust to the institution the first year resulting in his being significantly less effective as an instructor. Eaculty Organization challenges

Responses in this category were varied and tended to overlap with previous interview questions. Table 7 summarizes the participant's comments. Because participants were encouraged to interpret each question in light of their own first-year experience, this question was interpreted in many different ways.

Time spent on committees. Seven respondents commented on their involvement; or lack of involvement in committee work outside of their department meetings. Those data were examined in the previous section under shared governance. Eaculty laber unions. Five respondents addressed the idea of faculty unions. All five indicated that they had

Table 7

Eaculty Organization challenges

\begin{tabular}{|c|c|}
\hline Challenge Area & $\mathrm{N}$ \\
\hline Time Spent on Committees & 7 \\
\hline No Problem & 7 \\
\hline Faculty Labor Unions & 5 \\
\hline
\end{tabular}


been visited by union representatives, but did not feel pressure to join. Instead, the representative outlined the benefits as he or she saw them and left it at that.

other challenges. Interview question two ended by asking interviewees to name any other challenge areas that they would like to name. Seven participants added areas like: needed to be better informed about "how things really are, time management, getting to know the institution, the evaluation process, getting together with the assigned mentor, and better test writing skills." With the exception of the mentor and test writing comments, all of the other areas are incorporated in the previous research question discussion. Mentoring, and the difficulty some new faculty had with arranging meeting times with their mentors, is discussed in research question four. Interview Question Three

When dealing with the problems you just described, what was the greatest source of help to you? How did this source help you?

Although the question asked interviewees to pick the greatest source of help, most participants named two or more areas. In a few cases, respondents stated that the source of help depended on the problem. For example, one person said that if he had a problem with teaching strategy or techniques he sought the aid of peers. If he had a problem with his teaching assignment, he went to his department chairperson 
and if the problem was with administration he looked for help from the department dean.

Table 8 outlines the various sources of help during the first year of hire as reported by the participants. colleagues

Over half of the interviewees found that their colleagues were the greatest source of help. "Colleagues" included office partners (two responses), other new faculty (one response) and department colleagues (eight responses). The biggest help cited in the case of the office partner was that person's close proximity. Within the first year at a new institution, respondents indicated that as problems occurred it was nice to have someone close by with whom to confer. One interviewee explained:

My greatest help came from my office partner. Having someone who knew where the skeletons were buried; who was easily accessible to just kind of turning around in my chair in the office and ask when we were both there. It was having the proximity to someone who had the knowledge and the information in a non-threatening environment.

A number of respondents reported that it was helpful to have colleagues who were willing to discuss the political nature of the department and the school. Other participants found that colleagues "knew how to maneuver to get things done" and 
could answer questions related to the workings of the department.

Interviewees also reported that their associates gave valuable problem-solving advice. Many department colleagues had experience solving classroom challenges that were discipline specific. In some cases, colleagues had already worked through dilemmas and could offer insight to possible solutions.

Other new faculty members were found to be a source of help because they provided empathy and comradeship. One respondent found that he reduced his "new job" anxiety by talking to new faculty. He discovered that they were experiencing similar problems and tensions. The need for ways to build new-faculty comradeship is discussed again in interview question four.

Table 8

Sources $\Omega$ f Heln

Categories $\mathrm{N*}$

Colleagues

Department Chairperson 7

Department Secretary 4

Division Dean 3

Mentor Somewhat Helpful 3

Mentor Primary Source 2

*Note: Multiple Responses Given 


\section{Department chairperson}

Another source of problem-solving help noted by participants was the department chairperson. Although most interviewees stated that colleagues were the the best sources for insight into school politics, two participants indicated that helpful political information could also be gained from the department chairperson. Participants indicated that the department chairperson was supportive and a good source of problem-solving advice. One respondent's chairperson met with her before the orientation day and gave her a tour of the campus, satelite centers, and the surrounding area. The new instructor found this informal tour to be extremely helpful. In addition, she felt that she was in a better position to ask questions on orientation day because she already had a basic understanding of how the school operated. Department secretary

Four responses indicated that the department secretary was a valuable source of help. The consensus among respondents was that the secretary "knew how to make things go." In addition, secretaries were named as another source of information about department and school politics. Division Dean

Three responses indicated that the division dean was a good source of supportive help. In addition, one respondent found that her dean offered constructive criticism which helped to ease her assimilation into the department. 
Mentors

The first semester of hire, each site used in this study assigned a mentor to the new faculty member. However, only two respondents named their mentor as their primary source of support. Further examination of these two interviewees reveals that both respondents work at the same site, in the same department, and had the same mentor. In addition, their mentor was also their department chairperson. Possibly because the mentor and the department chair were the same person, this individual would have been named as a significant source of help even if she had not been also the assigned mentor. Three interviewees found their mentors "somewhat helpful" and liked the idea that the assigned mentor was a person outside of their department. One participant reported that he liked having a "safe" person outside of his program.

As discussed in the review of the literature, mentoring should be a special relationship of help, nurture and support. Most respondents indicated that their mentors were of no help to them. The reasons underlying this occurrence are explored further in the next interview question when participants give advice to their institutions. In the final chapter of this dissertation the researcher offers recommendations for administrators who wish to improve the effectiveness of the mentoring program. 
Interview Question Four

Let's assume that this college is interested in improving the support given to first-year faculty. What advice would you give this institution to help it better meet the needs of first year teachers?

This question generated a large variety of responses. The following tabies group responses according to the type of recommendation made. Table 9 summarizes suggestions that could be included in an orientation to the employing coliege, Table 10 looks at suggestions that could be responded to by individual departments. Tenure and evaluation comments are covered in Table 11 and suggestions directed toward the mentor program are summarized in Table 12. The data are not interpreted as commendations and/or recommendations for each site's specific orientation program. However, it is noted in the narrative when a particular comment was site specific, that is, all responses were generated by employees at a particular institution. orientation to the Institution

Table 9 lists the comments that interviewees made concerning their orientation to the employing college. The frequency of response is noted next to each comment.

Shorter orientation segments. The recommendation receiving the largest frequency of responses is the suggestion that an eight-hour, single day, orientation is not preferred by new hires. All respondents in this category 
were from a college using this type of format. One interviewee commented that because so much information was given in a single session, the orientation became "meaningless and a jumble of information." Develop a schematic chart of college levels. Participants indicated that a succinct schematic handout of the different department and administrative levels would have been helpful the first year of hire. In addition, interviewees requested that the names of department heads and administrators be included on the schematic along with a brief description of their job duties and responsibilities. Most informants stated that department heads and administrators introduced themselves during the orientation program, but that the chart could have been a useful supplement to the orientation day.

Organize a peer support group for new faculty. The suggestion that colleges should encourage new faculty members to meet regularly as a support group was articulated by four respondents. Other interviewees expressed positive feelings of comradeship toward other new hires, although they did not suggest an organized group meeting. For example, most participants stated that one of the facets they enjoyed most about the orientation process was that they were able to meet other new hires. One interviewee commented that even though everyone on campus seemed friendly, he "didn't feel at home 
Table 9

Suggestions for Orientation to the Institution

\begin{tabular}{ll}
\hline Categories & $\mathrm{N} *$ \\
\hline Shorter Orientation Segments & 4 \\
Schematic of College Levels & 4 \\
Peer Support Group for New Faculty & 4 \\
Tour of Campus and Community & 3 \\
Student Services & 2 \\
Verbal Overview of Faculty Manual & 2 \\
Separate Orientation for New Faculty & 2 \\
Film about Institutional History & 1 \\
Explain the Community College System & 1 \\
\hline
\end{tabular}

*Note: Multiple Responses Given

enough to stop and chit-chat" with many of the people he had met in his department. He related that it was much easier for him to talk to the other instructors he recognized as being new faculty members. Other interviewees observed that it was comforting to be able to share frustrations and anxieties with fellow faculty members who were going through similar experiences.

conduct a tour of the campus and community. Not all orientation programs included a tour of the campus, and respondents felt that this should be done early in the orientation process. According to one interviewee "When a 
person is hired, somebody--and I don't know who that somebody would be--should take them around to the different departments. Show them where things are on campus." One interviewee was given a tour of the surrounding community and satellite campuses by her department chairperson. She reported that the tour was one of the most helpful gestures made by the department. Another participant recommended that all new hires be taken on a campus tour and introduced to staff as a new faculty member.

Qutline services available to students. Two of the 19 respondents reflected that they would have liked a synopsis of the types of student support services available on campus. Both respondents felt unprepared and unable to offer information to needy students.

Give a verbal overview of the faculty manual. Only two interviewees suggested that a verbal overview of the faculty handbook be given. in the initial orientation session; however, several respondents indicated that they found the manual difficult to read. This comment was made by participants at all three sites. Respondents indicated that when they needed information, they did not turn to the faculty handbook but to a more approachable source like the faculty secretary. The two respondents in this category felt that they would be more likely to use the manual if they had been given a verbal overview of its contents and the kinds of helpful information they might find in it. 
Held a separate orientation session for new faculty. Two of the sites used in this study incorporate a separate orientation session for new faculty members. The respondents who suggested a separate orientation for new instructors are employed by the only site not using a separate new-faculty orientation. These interviewees participated in a Fall session designed for all returning staff and faculty. They felt that a separate time for introducing new-hires to the college would have been very helpful.

Show a film about the college and its history. One participant speculated that a film depicting the history of the college would have helped her to become more familiar with the culture of the college. This film could also introduce administrators and be the first exposure to who does what on the campus. It is interesting to note that this respondent teaches at the site not using a separate orientation session for new faculty members.

Offer a workshop about the community college system. One interviewee felt that a workshop explaining the community college system would have been a good way to help new hires gain a perspective of how their institution fit into the greater scheme of the community college system. Suggestions for the Department

Table 10 summarizes the suggestions given by participants with regard to orientation to their individual departments. 
erientation for part-time to full-time faculty. The transition from in-house part-time faculty to full-time status is not always easy. Respondents in this category felt that the transition would be less confusing if a department orientation had been given to them. The respondents in this category taught part-time at a particular site before being hired on a full-time basis. These three individuals found that full-time department members assumed that the new-hires "knew the ropes" because they had previously taught for the institution. As noted in an earlier section, a part-time teacher has a distinctive role within the department, that is decidedly different from the full-time instructor. One interviewee noted that "I didn't get much department orientation, perhaps because the department assumed I already knew what to do. But now it's a different focus."

Reduce the first semester teaching load. The interviewees contributing this comment were the same three with reduced teaching loads discussed in an earlier section. These respondents voiced their belief strongly that the reduced teaching assignment given to them the first semester contributed significantly to their increased productivity the first year of hire.

effice in close proximity to the department. It became clear to this researcher as interviews progressed that the first few semesters of hire are likely to be the time when 
Table 10

Suggestions for orientation to the Department

Categories $N$

Orientation for Part-Time

to Full-Time Faculty 3

Reduced Load First Semester 3

Office in Close

Proximity to Department 3

Handbook of "How-To's" 3

More Orientation to the Department 3

Explain Political Structure 1

Introduce New Person

through Social Gathering 1

the new person is in the most need of immediate departmental support. Some interviewees related that the first semester they were placed in an office whose previous inhabitant was on sabbatical leave. Often they were placed in an available space on campus. When that space was removed from the department, interviewees found it to be more stressful and inconvenient.

Handbook of "how-to's." This suggestion centers on the respondents' need to have a simplified, clear, departmentgenerated guideline explaining how things are done. This kind of handbook might address the process for changing a textbook, the procedure for creating and approving a new 
class, and similar items. One interviewee suggested that this guidebook should be written by a department faculty member and would supplement the faculty manual. As stated by one participant, "I needed information about what the job entails at the department level; who does what and where to go for information and services."

More orientation to the department. Respondents noted that, at least initially, they wanted more orientation to the department and less focus on orientation to the college. They wanted "the basics"--enough to get them into the classroom. One respondent noted that "I could have used more information about the actual functional structure of the department. How you 'plug in'; how you relate." Explain the political structure of the department. As mentioned in an earlier section, new hires are understandably concerned with grasping the political underpinnings of the institution and their department. One interviewee reflected that:

I wish there was a better way to be informed. I'm not sure how this could be done but new faculty should be informed of how things really are. With my department it's 'go off on your own and if you overstep your bounds we'll tell you'. 
Suggestions Regarding Tenure and Evaluation

Less than half of the interviewees had suggestions about the tenure process and the evaluation procedure. Table 11 summarizes these suggestions.

Table 11

Suggestiens Regarding Tenure and Evaluation

\begin{tabular}{ll}
\hline \hline Categories & $\mathrm{N}$ \\
\hline \hline Explain Tenure Process & 2 \\
Make Evaluation Less Intimidating & 2 \\
Explain Evaluation Procedure & 1 \\
Constructive Feedback on Evaluation & 1 \\
\hline
\end{tabular}

The six responses in this category are straightforward. The basic idea presented by respondents was that they wanted to be better informed about the tenure process and its evaluation component. Interviewees reported that tenure and evaluation explanations should be done in separate workshops a week or so into the first semester. Most sites included these explanations as part of the initial orientation meeting and as a result they became a part of the information overload as described in a previous section. 
Suggestions for the Use of Mentors

Few participants found the mentoring program to be of significant help to them the first year of hire. According to one interviewee "I think the program's valuable and there's a lot to be said for it, but it hasn't worked out for me." Table 12 outlines interviewee comments and advice about how the program could be made workable for more new instructors.

The mentoring relationship is explored in more detail in the next chapter; however, the suggestions presented in the above table offer advice which would have made the mentor/mentee experience more productive for the respondents. The fact that six different suggestions were generated from participants at all interview sites indicates that all sites have room to improve their mentoring program. For example, one interviewee stated that his mentor had only one year experience with the institution. The respondent understood the theory, in that the mentor was more likely to be empathetic, but in practicality he felt that someone with more experience would be able to "give the kind of insight to the history of the campus and political skeletons that new instructors need."

A key piece of advice offered by one interviewee was that mentors needed to be pro-active; that is, actively seek contact with the mentee and encourage the mentor-protege 
Table 12

Suggestions Regarding the Menter Pregram

Categories

$\mathrm{N}$

Use Experienced Faculty as Mentors

1

Pair Mentor/Mentee as Office Partners

1

Have Mentee Choose Mentor

1

Mentor Needs to be Pro-active

1

Don't Use Department Chair as Mentor

1

relationship. In an earlier discussion, it was noted that mentees did not often see their mentors and did not want to be bothersome by seeking extended contact. This respondent felt that it was the mentor's responsibility to contact the mentee and encourage discussion. Another participant wanted to pick her mentor. In her words:

Given my personal situation, I would rather have had someone more closely aligned to my field, so they kind of know my pressures more. I would have maybe even picked a female just because some of the adjustments going parttime to full-time have to do with juggling your personal Iife with the full-time commitment. It might have been nice just to talk to another woman that's a mother or married and trying to work full-time also. Also, how to establish relationships with male colleagues where you just want to make sure you do it in a professional way. 
Finally, the interviewees who commented on the mentoring program liked the idea of having a mentor assigned who taught in another discipline. Participants felt that they were less likely to step on toes and could speak more openly to someone outside their area. Not everyone felt this way, though. Two interviewees stated that because the mentor was outside their discipline, they had less in common and the relationship was less productive. It is interesting to note that the three respondents who named their mentor as being the greatest source of help, had mentors who were either their department chairperson or a department colleague.

Most interviewees agreed that the mentoring program is potentially a valuable source of support for new instructors. Most interviewees also felt that the program did not work for them. The suggestions given by participants could help instructional administrators to fine-tune and adapt the program to play a more significant role in aiding new faculty.

The previous discussion examined data generated by the interview questions. To tie this information together, a look at the research questions is in order.

The Research Questions Answered

The following four research questions provided the foundation for this study. Basically, this researcher sought to uncover the types of challenges experienced and sources of help given during the first year of hire. When considering 
the kinds of problems new teachers experienced, two variables were considered: (a) the size of the employing school and its effect on the kinds of problems experienced and, (b) the amount of previous teaching experience and its effect on the kinds of problems experienced. These variables are addressed in research questions two and three, respectively. Research Question one

What problems did new faculty experience in each of the following categories:
a. Students
b. Teaching load
c. Collegial relationships
d. Administration or college governance
e. Faculty organizations

Students. The largest response category in this area indicated that most participants reported that they had no student-related problems. At first, this seems to be surprising considering that the community college tends to attract a wide diversity of students. Actually, it is not surprising when one considers the data revealed in interview question--most participants had a background of teaching at least part-time with a community college, thus, they were prepared for the student diversity.

The next most frequently generated response had to do with student motivation and reasons for participation. Along the same line, participants found that there was often a 
difference between the motivational levels of day and night students and that student skill levels and ethnic diversity sometimes presented challenges in the classroom.

Teaching lead. Eleven respondents commented on teaching load-related challenges. In the discussion of research question three the relationship between previous community college experience and the perceived burden of the teaching load is discussed: That is, part-time community college teachers, hired on a full-time basis generally found that teaching full-time for a single school was less difficult than teaching the same number of hours on a part-time basis for several colleges.

Some interviewees found that they were given schedules that were awkwardly arranged; thus, the teaching load was acceptable but the way classes were scheduled made the load difficult. For example, one respondent taught two night classes that were followed by early day classes the next morning. Also, interviewees reported that when their teaching load was spread out between the main campus and satellite campuses the situation was challenging.

collegial relationships. The most commonly cited problem with regard to colleagues was isolation, both physical and emotional. Physical isolation occurred when the new hire's office was not in close proximity to the department or when teachers within the department had very different schedules. Emotional isolation occurred when new instructors were not 
introduced to department members and when instructors were new to the institution and did not feel comfortable seeking contact with colleagues.

Other problems in this category had to do with fitting into the department structure and dealing with disgruntled part-timers who were not hired for the full-time position. Some respondents, who had their teaching status changed from part to full-time, found that their department assumed that they needed little to no orientation because of their past association with the institution. This lack of orientation presented problems as new hires felt unprepared to advance to a full-time position.

Administration or college governance. The most common response categories were: (a) learning the political underpinnings of the institution and, (b) shared governance or time spent on committees. Many new hires were understandably concerned with unwittingly offending other instructors and administrators. Most felt that understanding the political agendas of their colleagues and school administrators was the single greatest challenge the first year of hire. The next largest response category addressed the time spent on committees as part of shared governance. Other problems voiced addressed areas such as, dealing with the evaluation and tenure processes; establishing credibility with administrators; and getting funding for instructional programs. 
Eaculty organization challenges. Most respondents interpreted "faculty organization" as committee work and were concerned with the amount of time they felt obligated to spend on committees. Even though all interviewees reported that they were encouraged to avoid committee work their first semester, some felt that it would contribute positively to their pursuit of tenure. These responses were discussed in greater in the previous section under "shared governance." An equal number of responses indicated that participants had no problems with faculty organizations the first year of hire. Most were approached by labor union representatives, but none felt pressured to join.

Research Question Two

Did the size of the employing school affect the kinds of problems experienced?

To answer this question, the following discussion offers five tables that examine responses to each challenge area. Each table presents the total number of responses given to each challenge area and then shows a breakdown of the component number of responses by site. This discussion begins with student challenges.

Students. Table 13 reveals that participants at Sites 2 and 3 had the highest percentage of responses reporting no problems with student diversity. In addition, half of the interviewees at site 3 reported student-related challenges when dealing with day and night students. Because site 3 is 
a small college and has less faculty to handle teaching hours, four of the six interviewees taught night as well as day classes. Two participants at site 1 taught night classes, with one interviewee reporting a problem adapting classes to meet the needs of day and night students. At Site 2, two participants taught night classes and one interviewee reported that there was a challenging difference between day and night students. Based on these responses it is possible to conclude that instructors who teach evening classes will encounter challenges when adapting course material to meet the different needs of day and night class learners.

Table 13

Student Diversity Challenges Presented by Site

\begin{tabular}{|c|c|c|c|c|}
\hline \multirow[b]{2}{*}{ Challenge Area } & \multicolumn{4}{|c|}{$\mathrm{N} *$} \\
\hline & & $\begin{array}{c}\text { Site } 1 \\
\mathrm{~N}=8 \\
\end{array}$ & $\begin{array}{c}\text { Site } 2 \\
\mathrm{~N}=5 \\
\end{array}$ & $\begin{array}{c}\text { Site }{ }^{3} \\
\mathrm{~N}=6 \\
\end{array}$ \\
\hline No Problem & 9 & 3 & 3 & 3 \\
\hline Reasons for Participation & 5 & 2 & 1 & 2 \\
\hline Day vs. Night Students & 4 & 1 & 0 & 3 \\
\hline Skill Levels & 3 & 1 & 1 & 1 \\
\hline Ethnic Diversity & 1 & 1 & 0 & 0 \\
\hline
\end{tabular}

*Note: Multiple Responses Given

Teaching load. Table 14 reviews the responses about teaching load the first year of hire and divides the data by 
site. This table reveals that three out of the six participants from site 3 reported that their teaching hours were awkwardly arranged. Because site 3 is a small college, it is possible that there is less flexibility in the arrangement of teaching hours, which could explain the complaint about difficult teaching schedules. Finally, three participants at Site 1 were given a reduced teaching load the first semester of hire. All three interviewees found the reduced teaching hours especially helpful and felt that they were more effective the first semester.

Table 14

Teaching Ioad challenges presented by site

\begin{tabular}{|c|c|c|c|c|}
\hline \multirow[b]{2}{*}{ Challenge Area } & \multicolumn{4}{|c|}{$\mathrm{N}$} \\
\hline & & $\begin{array}{c}\text { Site } 1 \\
\mathrm{~N}=8 \\
\end{array}$ & $\begin{array}{c}\text { Site } 2 \\
\mathrm{~N}=5 \\
\end{array}$ & $\begin{array}{c}\text { Site } 3 \\
\mathrm{~N}=6 \\
\end{array}$ \\
\hline Too Heavy & 6 & 2 & 2 & 2 \\
\hline Full-Time Easier to Manage & 4 & 1 & 2 & 1 \\
\hline Manageable but Challenging & 3 & 2 & 1 & 0 \\
\hline Reduced First Semester & 3 & 3 & 0 & 0 \\
\hline Hours Awkwardly Arranged & 2 & 0 & 0 & 2 \\
\hline No Problem & 1 & 0 & 0 & 1 \\
\hline
\end{tabular}

Collegial relationships. Table 15 presents the response categorization per site with regard to collegial relationships. This table illustrates that the most 
frequently cited challenge area at site 2 was isolation.

Site 2 is a large, single-college district with several

education centers. The first semester of hire some

interviewees had a portion of their teaching hours scheduled

at education centers instead of on the main campus. This

situation led to the emotional and physical isolation

experienced by respondents at this site. Sites 1 and 3 had a

more even distribution of problem areas and both had some

new-hires who reported "no problem" with collegial

relationships.

Table 15

Collegial Relationship Challenges Rresented by Site

\begin{tabular}{|c|c|c|c|c|}
\hline \multirow[b]{2}{*}{ Challenge Area } & \multicolumn{4}{|c|}{$\mathrm{N}$} \\
\hline & & $\begin{array}{c}\text { Site } 1 \\
\mathrm{~N}=8\end{array}$ & $\begin{array}{c}\text { Site } 2 \\
\mathrm{~N}=5\end{array}$ & $\begin{array}{c}\text { Site } 3 \\
N=6\end{array}$ \\
\hline $\begin{array}{l}\text { Isolation } \\
\text { (Physical and Emotional) }\end{array}$ & 6 & 1 & 3 & 2 \\
\hline No Problem & 5 & 2 & 0 & 3 \\
\hline $\begin{array}{l}\text { Relationships with } \\
\text { Department Members }\end{array}$ & 3 & 3 & 0 & 0 \\
\hline $\begin{array}{l}\text { Fitting into } \\
\text { Department Structure }\end{array}$ & 3 & 2 & 0 & 1 \\
\hline Responsibility to Department & 2 & 0 & 2 & 0 \\
\hline
\end{tabular}


Administration or college governance. Table 16 presents a look at administration-focused problems as reported by site.

Site 1 was the only site to report "no problems" with administration and college governance. As explained in Chapter Three this site's college president takes an active role in new-faculty orientation which could explain the response. On the other hand, site 1 was also the only site to have respondents report credibility problems with administrators. Another response that was site specific was the funding problem articulated by interviewees at site 3 . Again it is unwise to state conclusions based on a small Table 16 Administration or college Governance challenges Presented by Site

\begin{tabular}{|c|c|c|c|c|}
\hline \multirow[b]{2}{*}{ Challenge Area } & \multicolumn{4}{|c|}{$\mathrm{N} *$} \\
\hline & & $\begin{array}{c}\text { Site } 1 \\
\mathrm{~N}=8 \\
\end{array}$ & $\begin{array}{c}\text { Site } 2 \\
\mathrm{~N}=5\end{array}$ & $\begin{array}{c}\text { Site } 3 \\
\mathrm{~N}=6 \\
\end{array}$ \\
\hline Politics & 7 & 2 & 2 & 3 \\
\hline Shared Governance & 7 & 1 & 3 & 3 \\
\hline Evaluation/Tenure Process & 4 & 0 & 1 & 3 \\
\hline No Problem & 4 & 4 & 0 & 0 \\
\hline $\begin{array}{l}\text { Credibility } \\
\text { with Administrators }\end{array}$ & 3 & 3 & 0 & 0 \\
\hline Funding & 2 & 0 & 0 & 2 \\
\hline
\end{tabular}

*Note: Multiple Responses Given 
sample size. It is this researcher's opinion that the specific problems just mentioned are more likely to be a function of the site's administrative governance style instead of its size.

Eaculty organizations. There were no site-specific problems in the category of faculty organization challenges. At Site 1 two out of eight respondents reported that fitting committee work into their schedules was challenging. At Site 2 the percentage was higher--three out of five interviewees reported that committee work presented a challenge. It should be noted that first-year faculty found it difficult to fit committee work into their already busy schedules.

Table 17

Eaculty Organization challenges Presented by site

\begin{tabular}{llccc}
\hline & \multicolumn{4}{c}{$\mathrm{N}$} \\
\cline { 2 - 5 } Challenge Area & & $\begin{array}{c}\text { Site } \\
\mathrm{N}=8\end{array}$ & $\begin{array}{c}\text { Site } \\
\mathrm{N}=5\end{array}$ & $\begin{array}{c}\text { Site } 3 \\
\mathrm{~N}=6\end{array}$ \\
\hline Time Spent on Committees & 7 & 2 & 3 & 2 \\
No Problem & 7 & 3 & 1 & 3 \\
Faculty Labor Unions & 5 & 3 & 1 & 1 \\
\hline
\end{tabular}

Responses to the last research question (did the size of the employing school affect the kinds of problems experienced?) show that in two areas the school size did make 
a difference in the types of problems reported. First, two out of six respondents, employed by the smallest school site, reported awkwardly arranged teaching schedules; and second, three out of five interviewees at the largest school site experienced emotional and physical isolation the first year of hire. The next research question asks if prior teaching experience affects the types of problems reported by new faculty during the first year of hire. Research Ouestion Three

Did the amount of previous teaching experience affect the kinds of problems experienced?

The discussion generated by research question three will be aided by tables similar to those used in the previous section. Again, the responses to each challenge area are summarized by a table reporting the total number of responses and the component numbers are sectioned according to interviewee experience.

Students. Table 18 analyzes student diversity challenges and respondents prior teaching experience. The most obvious pattern to note on this table is each of the nine respondents indicating that they had "no problems" with student diversity had prior teaching experience at a community college. As noted in an earlier section, these interviewees qualified their responses with comments indicating that they were familiar with the types of students that the community college attracts. The other problem areas--student 
Table 18

Students Diversity Challenges Presented by Participant Teaching Experience

\begin{tabular}{|c|c|c|c|c|c|}
\hline \multirow[b]{2}{*}{ Challenge Areas } & \multicolumn{5}{|c|}{$\mathrm{N} *$} \\
\hline & & $\begin{array}{l}\text { No } \\
\text { C.C. } \\
\text { Exp. } \\
\end{array}$ & $\begin{array}{c}\mathrm{P} / \mathrm{T} \\
\text { at } \\
\text { site } \\
\end{array}$ & $\begin{array}{c}\mathrm{P} / \mathrm{T} \\
\text { not at } \\
\text { Site } \\
\end{array}$ & $\begin{array}{r}F / T \\
C . C \\
\text { Exp. }\end{array}$ \\
\hline No Problem & 9 & 0 & 6 & 2 & 1 \\
\hline Student Participation & 5 & 3 & 0 & 2 & 0 \\
\hline Day vs. Night Students & 4 & 3 & 0 & 1 & 0 \\
\hline Skill Levels & 3 & 2 & 1 & 0 & 0 \\
\hline Ethnic Diversity & 1 & 0 & 1 & 0 & 0 \\
\hline
\end{tabular}

*Note: Multiple Responses Given

C.C. = Community College

Exp. = Experience

$\mathrm{P} / \mathrm{T}=$ Part-Time

$F / T=$ Full-Time

participation, day vs. night students, student skill levels, and ethnic diversity--are all distributed evenly among the experience categories.

Teaching load. Table 19 examines the effect that previous teaching experience has on perceived problems with teaching load the first year of hire.

Two observations are apparent when reviewing Table 19. One, is that the participant with previous full-time community college teaching experience was the only respondent to report "no problems" with teaching load. Even those 
Table 19

Teaching Ioad challenges Presented by Participant Teaching Experience

\begin{tabular}{lccccc}
\hline \hline & \multicolumn{5}{c}{$\mathrm{N}^{*}$} \\
\cline { 2 - 6 } & & $\begin{array}{c}\text { No } \\
\text { C.C. } \\
\text { Exp. }\end{array}$ & $\begin{array}{c}\mathrm{P} / \mathrm{T} \\
\text { at } \\
\text { Site }\end{array}$ & $\begin{array}{c}\mathrm{P} / \mathrm{T} \\
\text { not } \\
\text { Site }\end{array}$ & $\begin{array}{c}\mathrm{E} / \mathrm{T} \\
\mathrm{C} . \mathrm{C} \\
\text { Exp. }\end{array}$ \\
\hline \hline Too Heavy & 6 & 3 & 0 & 3 & 0 \\
Full-Time Easier to Manage & 4 & 0 & 4 & 0 & 0 \\
Manageable but Challenging & 3 & 0 & 3 & 0 & 0 \\
Reduced First Semester & 3 & 1 & 2 & 0 & 0 \\
Hours Awkwardly Arranged & 2 & 1 & 0 & 1 & 0 \\
No Problem & 1 & 0 & 0 & 0 & 1 \\
\hline
\end{tabular}

*Note: Multiple Responses Given

C.C. = Community College

Exp. = Experience

$\mathrm{P} / \mathrm{T}=$ Part-Time

$F / T=$ Full-Time

respondents with full-time teaching experience at other types of collegiate institutions (four-year universities and private schools) experienced some type of teaching load problem.

The second observation is that all respondents reporting that a full-time teaching load was easier to manage than a similar load at various colleges, were part-time faculty at the employing institution before they were hired full-time. Also, all respondents stating that the first year 
teaching load was challenging but manageable had previous part-time experience at the employing site. These observations are not particularly surprising, but they are noteworthy because all respondents in the category possess similar teaching experience backgrounds. Finally, those interviewees with no community college teaching experience reported problems with the teaching load being too heavy, and the teaching hours being awkwardly arranged.

collegial relationships. Table 20 reports collegial relationship problems that are separated into categories defined by participant previous teaching experience.

Table 20

Collegial Relationship Challenges Presented by Participant Teaching Experience

\begin{tabular}{|c|c|c|c|c|c|}
\hline \multirow[b]{2}{*}{ Challenge Areas } & \multicolumn{5}{|c|}{$\mathrm{N}^{*}$} \\
\hline & & $\begin{array}{l}\text { No } \\
\text { C.C. } \\
\text { Exp. } \\
\end{array}$ & $\begin{array}{r}\mathrm{P} / \mathrm{T} \\
\text { at } \\
\text { Site } \\
\end{array}$ & $\begin{array}{c}\mathrm{P} / \mathrm{T} \\
\text { not at } \\
\text { Site } \\
\end{array}$ & $\begin{array}{l}F / T \\
\text { C.C. } \\
\text { Exp. } \\
\end{array}$ \\
\hline Isolation & 6 & 2 & 1 & 2 & 1 \\
\hline No Problem & 5 & 0 & 3 & 2 & 0 \\
\hline $\begin{array}{l}\text { Relationships with } \\
\text { Department Members }\end{array}$ & 3 & 3 & 0 & 0 & 0 \\
\hline $\begin{array}{l}\text { Fitting into } \\
\text { Department Structure }\end{array}$ & 3 & 2 & 1 & 0 & 0 \\
\hline Responsibility to Department & 2 & 0 & 2 & 0 & 0 \\
\hline
\end{tabular}

*Note: Multiple Responses Given 
One observation drawn from Table 20 is that all respondents reporting problems with other department members had no previous community college teaching experience. As noted in an earlier discussion, the nature of the problems were such that the new faculty members felt silent, passive hostility from other department members; many of whom were part-timers not hired for the full-time position. One could speculate that the hostility sprang from the feeling that an "outsider" had entered the department and had taken a job rightfully belonging to an adjunct faculty member who had already put in time with the institution. The only other category to have all respondents possess the same teaching background is the section addressing the changing feeling of responsibility to the department felt by in-house, part-time faculty going to a full-time status. This, too, is not surprising, but indicates that there is a consistency between teaching experience within the community college system and the types of problems experienced.

Administration or college governance. Previous teaching experience does not seem to affect the problems new hires have with college governance. Table 21 illustrates that the problem areas are fairly evenly distributed among the teaching experience categories.

Eaculty organizations. Table 22 shows that previous teaching experience seems to have no affect on interviewees perceived problems with faculty organizations. 
It is apparent that previous teaching experience does impact on the types of problems reported by participants. The research question asked if the "amount" of previous teaching experience affected the kinds of problems experienced. Based on the data presented in Table 22 it seems that the amount of experience does not make a difference, but the kind of experience does. Research question four outlines the kinds of resources that new faculty found helpful.

Table 21

Administration or college Governance challenges Presented by Participant Teaching Experience

\begin{tabular}{|c|c|c|c|c|c|}
\hline \multirow[b]{2}{*}{ Challenge Areas } & \multicolumn{5}{|c|}{$\mathrm{N}^{\star}$} \\
\hline & & $\begin{array}{l}\text { No } \\
\text { C.C. } \\
\text { Exp. }\end{array}$ & $\begin{array}{r}\mathrm{P} / \mathrm{T} \\
\text { at } \\
\text { Site } \\
\end{array}$ & $\begin{array}{c}\mathrm{P} / \mathrm{T} \\
\text { not at } \\
\text { Site }\end{array}$ & $\begin{array}{l}F / T \\
C . C . \\
\text { Exp. }\end{array}$ \\
\hline Politics & 7 & 1 & 3 & 3 & 0 \\
\hline Shared Governance & 7 & 2 & 3 & 1 & 1 \\
\hline Evaluation/Tenure Process & 4 & 0 & 0 & 3 & 1 \\
\hline No Problem & 4 & 2 & 2 & 0 & 0 \\
\hline $\begin{array}{l}\text { Credibility } \\
\text { with Administrators }\end{array}$ & 3 & 2 & 1 & 0 & 0 \\
\hline Funding & 2 & 0 & 0 & 2 & 0 \\
\hline
\end{tabular}

*Note: Multiple Responses Given

C.C. = Community College

Exp. = Experience

$\mathrm{P} / \mathrm{T}=$ Part-Time

$\mathrm{F} / \mathrm{T}=$ Full-Time 
Table 22

Eaculty erganization challenges Presented by Participant Teaching Experience

\begin{tabular}{|c|c|c|c|c|c|}
\hline \multirow[b]{2}{*}{ Challenge Areas } & \multicolumn{5}{|c|}{$N *$} \\
\hline & & $\begin{array}{l}\text { No } \\
\text { C.C. } \\
\text { Exp. }\end{array}$ & $\begin{array}{c}\mathrm{P} / \mathrm{T} \\
\text { at } \\
\text { Site } \\
\end{array}$ & $\begin{array}{c}\mathrm{P} / \mathrm{T} \\
\text { not at } \\
\text { Site } \\
\end{array}$ & $\begin{array}{l}F / T \\
\text { C.C. } \\
\text { Exp. }\end{array}$ \\
\hline Time Spent on Committees & 7 & 2 & 3 & 1 & 1 \\
\hline No Problem & 7 & 1 & 4 & 2 & 0 \\
\hline Faculty Labor Unions & 5 & 2 & 1 & 2 & 0 \\
\hline $\begin{array}{l}\text { C.C. }=\text { Community } \\
\text { Exp. = Experience } \\
\text { P/T = Part-Time } \\
\text { E/T }=\text { Full-Time }\end{array}$ & & & & & \\
\hline
\end{tabular}

Research Question Four

What kinds of things (people, programs, etc.) did new faculty name as being helpful during the first year of hire?

Most new faculty named department colleagues as their primary source of help during the first year of hire. Specifically, colleagues helped new hires to problem-solve and to uncover the political and functional structure of their department and school. The next largest response category was that which named the department chairperson as the primary source of help. Respondents citing this category felt that the chairperson was most helpful in explaining political underpinnings and the most expeditious way to get things done. Finally, this category showed that the 
mentoring program was not named as a useful source of support in most cases.

\section{Summary}

The data presented herein were gathered through interviews with 19 full-time, tenure-track, community college faculty. Interview questions asked participants to describe their challenges and sources of support the first year of hire. The researcher analyzed audiotaped records of the interviews and grouped responses into challenge categories. The emergent categories are reported via response frequency tables. Each table is supplemented with a narrative and when appropriate, quotes are used to provide clarity and emphasis. The next chapter provides a summary of the salient factors as emerged from the data analysis. In addition, researcher conclusions are reported and recommendations are given. 


\section{CHAPTER FIVE}

Summary, Conclusions, and Recommendations Introduction

Minimal research has been done about first-year community college faculty. This observation takes on added importance when one considers that over the next decade and a half approximately 18,000 new faculty members will be hired to teach in community colleges (Wisniewski, 1990). As supported by the review of literature, there is a continuing need not only for research about this growing populous of educators, but also for research that links theory and practice. The data presented in this study build toward achieving "praxis" or action working with theory (Foster, 1986). This study examines the needs of new instructors. In interviews, tenure-track, community college teaching faculty were asked to describe their problems and sources of help the first year of hire. An analysis of audiotaped interviews provided the data to develop themes surrounding reported experiences. From the reported themes a set of conclusions were developed and it is these conclusions that form the basis for recommendations presented in the last part of the chapter. The purpose of this study is to examine the experiences of first-year community college teachers. The value of the 
study is found in its reporting of challenges and sources of support as articulated by new hires. The study data are drawn from real-world experiences that in turn form the foundation for possible action by college leaders.

The scope of the study is such that all college leaders should benefit from its findings. For example, instructional administrators may examine their orientation and support programs for new faculty in light of this study's recommendations. Also, this dissertation provides department leaders with a clearer picture of the kinds of support that new faculty are likely to require. The findings presented in this study should enable any faculty or staff member, regardless of position, to assist new instructors more effectively. Finally, this study presents an insight into community college teaching that could be of interest to anyone considering a career as a community college instructor.

This chapter presents first, a summary of experiential themes; second, a listing and discussion of several conclusions; third, recommendations for possible action by college leaders; and finally, implications for further research.

\section{Summary}

The following is a summary of salient factors that emerged from the data analysis: 
1. Instructors having no previous community college teaching experience are likely to be challenged by student diversity within the classroom.

2. Instructors having no previous community college teaching experience are likely to have difficulty managing the number of teaching hours the first year of hire.

3. Instructors having no previous community college teaching experience are likely to experience emotional isolation with regard to colleagues and to encounter difficulty in relationships with other department members.

4. The size of the employing school affected the types of problems experienced by new faculty in two ways: first, some interviewees at site 3 (the small, suburban college) reported problems with awkwardly arranged teaching hours and with adapting course material to meet the differing needs of day and night students; and second, most new instructors at the largest school site (Site 2) reported feeling emotional and physical isolation the first year of hire. 5. The amount of previous teaching experience does not play a significant role in the types of problems reported, but the type of experience does. Instructors having taught at least part-time for a community college 
seem to have an easier time adjusting to student diversity and the first year teaching load.

6. The assigned mentor program was not named by participants as a significant source of help. 7. Proximity and likeness of purpose seem to play a major role in perceived sources of help the first year of hire. Most respondents named department colleagues as their primary source of help the first year.

conclusions

The following discussion of related conclusions first examines the two independent variables incorporated into the study: amount of prior teaching experience and size of the employing institution. The second part revisits participant suggestions for improving the support given to first-year faculty. These suggestions build the foundation for the recommendations given at the end of this chapter. Independent Variables.

This study was designed to explore the problems experienced by new community college faculty during the first year of hire. Within this exploration two variables were incorporated: (a) amount of prior teaching experience, and (b) size of the employing school.

The amount of teaching experience did not affect the kinds of problems reported, but the type of teaching experience did. That is, new instructors who previously had taught on a full-time basis for private and public 
institutions experienced difficulties that were not experienced by participants with only part-time experience teaching for a community college.

The second variable in this study was the size of the employing school. An analysis of responses to the challenge categories of "students", "teaching load", "collegial relationships", and "college administration and governance" reveals several conclusions. First, at site 3 (the small, suburban college) some interviewees reported problems with adapting course material to meet the differing needs of day and night students. It was noted that because it is small, Site 3 made more use of new faculty to teach night classes than did the other two sites. It is possible that if more interviewees had evening courses in their teaching load they might have also mentioned this challenge area. Also at Site 3, some participants mentioned that their teaching hours were awkwardly arranged. Because of the small teaching faculty it is possible that the site does not have the flexibility of a larger school when arranging teaching schedules.

Most new instructors at the largest school site (Site 2) reported feeling emotional and physical isolation the first year of hire. It was noted that some interviewees had a portion of their teaching hours scheduled at education centers instead of on the main campus. This situation led to the emotional and physical isolation experienced by respondents at this site. 
Rarticipant Suggestions

Student diversity. All participants without community college teaching experience named student diversity as a first-year challenge. Participants with a prior teaching background at a community college reported little or no difficulty with student diversity. It is interesting to note that all who gave a "no problem" response referred to their prior experience in dealing with community college students as the basis for their reply. Implicit in this "I don't have a problem with students now" reply is the suggestion that perhaps during their very first year of teaching at a community college student diversity was a challenge. It is probable that interviewees reporting "no problems" with student-related challenges deal with student diversity on a daily basis. It is possible that they have developed teaching strategies to cope with diversity and now do not consider it a problem. If the interview question had been rephrased such that interviewees were asked to comment specifically on skill levels, motivational and ethnic diversity, it is likely that all interviewees, regardless of previous community college teaching experience, would have addressed student diversity in the classroom.

Teaching load. Participants with prior community college teaching experience reported having few or no problems dealing with their teaching hours the first year. It is quite possible that their familiarity with the community 
college system, and in some cases the employing institution, contributed positively to their ability to cope the first year. It should be noted that participants with no previous community college teaching experience also had to relocate to a new city to accept the job assignment. Logically, this means that they had the normal stress of starting a new job compounded by moving themselves and sometimes their families to the area. Most nen faculty with no previous community college teaching experience reported that their first-year teaching load was overwhelming. It is prudent to take into account that the lack of familiarity with the community college system is probably not the only factor affecting the challenge category of "teaching load." To this end, one respondent stated that it was difficult to determine how much of the stress was due to the teaching load and how much was due to being new to the school and the area.

culture and politics. Of major concern to nearly all respondents was the task of learning the political underpinnings of the department and the institution. What most participants described as "politics" could also be described as learning the culture of the college. Schein (1986) defined culture as:

a pattern of basic assumptions-invented, discovered, or developed, by a given group as it learns to cope with its problems of external adaptation and internal integration-that has worked well enough to be considered 
valid and, therefore, to be taught to new members as the correct way to perceive, think, and feel in relation to those problems. (p. 9)

Respondents received their cultural indoctrination from a variety of sources: department colleagues, department chairpersons, office partners, and department secretaries. There was a positive correlation between those people reported as being most helpful and those that provided the greatest amount of insight to the culture of the college. That is, the person named as being most helpful the first year was usually the person who provided the greatest insight into the workings of the institution.

Mentoring. Most respondents did not name their assigned mentors as a helpful sources of support the first year of hire. This observation warrants a closer examination; especially when one considers that the idea of a mentor who is not helpful is actually a contradiction of terms. Most respondents agreed that their mentor was pleasant, but a mentor-mentee relationship did not develop. Participants gave several reasons why this happened. Interviewees related that their mentors had schedules very different from their own, thus it was difficult to meet. Other participants reported that because their mentors were relatively inexperienced (second-year teachers at the institution) they were unable to provide the kind of insight that comes with extended association with the college. One respondent 
quantified the amount of experience needed and said that in his opinion a mentor should have at least four years prior teaching experience at the institution. Finally, a few interviewees reported that their mentors seemed to be merely filling an obligation and not genuinely interested in developing a mentor-mentee relationship. It is possible that all respondents did participate in a mentoring relationship during the first year of hire--but in most cases not with the assigned mentor. The next section will explore this point further.

Every respondent named someone as their greatest source of help. They reported that this source helped them problemsolve, adapt to student demands, and understand the functional and political workings of the institution. This list seems very much like what Daresh and Playko (1989) outlined as the most important responsibilities of a mentor; to advise, communicate, counsel, guide, model, protect, and assist the protege in learning skills needed to carry out the job effectively (pp. 21-22). The support relationships described by participants were self-selective. The mentormentee relationship developed naturally with someone accessible to the new hire and who offered useful information. One participant reported that the assigned mentor program would have worked more positively for her if she had been able to chose her mentor. Million (1988) advised that when time and other logistical constraints 
permit, mentors and mentees should be permitted to select one another. He also contended that mentors should be formally trained and described a one-day formal training program as an alternative to long-term mentor training. Daresh and Playko (1989) also supported the idea of mentor training and offered a model of their own.

Participants reported a feeling of emotional isolation the first year on board. According to Million (1989) mentors should provide proteges with emotional support. In addition, mentors should be "accessible, interested, and willing to help" (Million, p. 8). Most participants felt that the mentor program should be continued, but that changes needed to be made.

New-faculty support groups. Participants reported that a peer support group the first semester on board would have been helpful. Eison and Hill (1990) reported that "there is evidence on our campus, though not formally verified, suggesting that friendships formed between members of nonrelated disciplines during a new-faculty workshop are among the most lasting benefits of the program" (p. 22). In an earlier publication, Eison and Hill stated that a key objective when designing new-faculty workshops was to build collegiality and comradery among new faculty. They suggested that workshop planners "provide ample time and opportunity for participants to meet and get to know their fellow new colleagues from across the campus" (1990, p. 231). 
Daresh and Playko (1989) referred to colleagues joining together as "peer pals", "someone at the same level as yourself with whom you share information, strategies, and mutual support for mutual benefit" (p. 21). Although the "peer pal" relationship was not a mentoring one per se, Daresh and Playko pointed out that a number of positive benefits could result just the same. Organizing a set meeting time and place for new faculty could be a way to develop a kind of "peer pal" relationship and an additional source of emotional support.

erientation. Participants who were concerned about their orientation gave several suggestions: (a) that orientation should not be given in an eight-hour block, (b) that initially, orientation should focus on the basics and (c) that orientation should provide more time for the new hire to be introduced to the workings of the department. Each of these suggestions are examined in more detail in the following section.

The need for pacing and breaking-up the massive amounts of orientation information was another suggestion offered by respondents. Interviewees suggested different methods for presenting the new information. For example, a verbal overview of the faculty manual was suggested as a way to alert new faculty to its contents; thus, making it easier to find information when a need arose. Schematic diagrams of the college departments and programs along with the names of 
the administrators in charge was suggested. Finally, a film explaining the college history and describing the surrounding community was mentioned as an interesting way to introduce the new hire to the institution and to the community. All of these suggestions were recommended by participants as potentially useful ways to help the new teacher to not only retain orientation information but to better grasp how to access information as the need for it arose.

One participant suggested that there be a pre-orientation meeting between the department chairperson and the new instructor. She related that her department chairperson had taken the time before orientation to show her the college and and brief her on basic campus history. As a result, she attended the new-faculty orientation with some knowledge about the institution and was able to ask informed questions during orientation; thus, making effective use of the orientation time. Some participants stated that they did not know enough to ask questions during orientation. They could only sit and try to absorb what was being presented.

The concept of "basics first" was supported by Eison and Hill (1990) who contended that new faculty operate on a Maslow-like hierarchy of needs. That is, they will be motivated to satisfy basic needs before an interest develops in higher level needs. For example, the basic needs would include pay, parking stickers, and teaching schedule information and the higher order would include promotion and 
tenure. The authors suggested that orientation programs be arranged in this hierarchy. Participants expressed a similar need for basic information first when they recommended less of an introduction to everyone on staff (stating that they wouldn't be able to remember their faces and names anyway) and more of an orientation to their departments.

An observation about the orientation programs in place at the three interview sites tends to support the importance of a strong department orientation. One of the sites used in the study does not have a separate orientation for new faculty. New hires are invited to the fall-semester orientation that is designed to acquaint all staff and faculty with the college goals, philosophy and mission for the coming year. After this orientation, the new instructors are sent to meet with their departments. This system is quite different from the other two sites who both have programs specially designed for new faculty, and yet the newhires at this site did not report problems that were very different from problems at the other sites. The next section of this chapter outlines several recommendations drawn from the conclusions and discussion just presented.

\section{Recommendations}

1. Give New Faculty the opportunity to Evaluate the Qrientation Program 
Eison and Hill (1990) suggested that administrators take the time to collect program evaluation data from participants. They advised that participant evaluation is a good way to identify areas needing further refinement and improvement. Based on data gathered in this study, it is recommended that instructional officers use anonymous feedback to double-check the effectiveness of orientation activities.

\section{Break Orientation Information inte Modules of Three} or Less Heurs

Break orientation information into modules that are presentec before and throughout the first semester of hire. Using information modules at different times during the semester gives instructional administrators the flexibility to tailor the orientation program to meet the differing needs of new instructors. Administrators planning orientation programs should keep in mind and apply basic teaching/learning strategies. That is, break-down complex blocks of information into manageable units and use varied methods of presentation to hold attention and foster learning. The advice of Eison and Hill (1990) support this recommendation. They advised that administrators use active learning strategies and provide a mix of individual, small group, and large group activities within new-faculty workshops. 


\section{Arrange Orientation Modules According to the Basic}

Needs of Participants

Interview responses suggest the following progression of information modules. First, conduct a pre-service orientation where new hires would meet the college president and the vice-president of instruction and other new faculty. A handbook would be given, but explained at a later time. Participants would be encouraged to explore the handbook at their convenience. Participants should spend the majority of the time with the department chairperson, learning about the district and the school from the department perspective. A second module might address tenure, evaluation, and the related processes. This could be done the second week of the semester. As support for this suggestion, one interviewee reported that the evaluation and tenure process needed to explained more clearly. A look at the orientation agenda for the site revealed that a significant amount of time was devoted to explaining these items. Perhaps the administrator giving the explanation was not clear or perhaps the information was lost in the information over-load of the initial orientation session.

Finally, a third module (perhaps three weeks into the semester) might introduce administrators (e.g.) head of student services, counseling, other vice-presidents and deans. At this time the faculty handbook might be overviewed and it is likely that by this time new hires have already run 
into problems and would have questions about the college and how it is run.

4. Give New Faculty a Tour of the Campus, Satelite Centers, and the Surrounding community

A tour of the campus and satellite centers is a good way to introduce new faculty to staff and to build a sense of integration with the institution. If possible, a resource guide to local businesses and services should be provided to instructors new to the area.

5. Avoid Giving New Faculty "Ieftover" Teaching Hours

Sometimes new instructors are assigned the teaching hours not desired by tenured faculty. The resulting schedule can be awkward and compound the probiems that normally occur when someone is new to an institution.

6. Place the New Instructor's office in close Proximity to Department colleagues and staff

Assigning an office close to other department faculty is a good way to decrease the likelihood that the new instructor will experience emotional and physical isolation. In addition, new faculty will be more likely to obtain needed assistance from colleagues and department staff members. 


\section{Encourage College Staff to Assume a Mentoring} Attitude Toward New Faculty.

This study has shown that the assigned mentor program usually does not result in the development of a mentor-mentee relationship. Therefore, the program should be supplemented by support from everyone on staff at the institution.

8. Give Assigned Mentors and Their Proteges Released Time

Respondents complained that it was difficult to schedule a time to meet with his or her mentor. A reduced teaching load for both the mentor and mencee would increase the likelihood that contact is made and that a mentoring relationship is developed.

\section{Provide Mentor Training}

Mentors should be carefully chosen and trained. Most respondents preferred mentors outside of their department and this seems to be a valuable suggestion. Daresh and Playko (1989) advocated training mentors in techniques designed to encourage the mentor-mentee relationship. They suggested that mentors be trained in trust building, open communication skills, adult learning theory, problem-solving skills, conferencing skills, and observation skills. Million (1988) wrote that both mentors and proteges could benefit from a mentor training programs. 
10. Use Tenured Faculty as Mentors.

Using mentors who are tenured faculty at the institution is recommended. Even though the use of second-year faculty as mentors may encourage an empathetic relationship, a more experienced mentor could give greater insight into the workings of the college. The need for information about the workings of the institution was clearly stated by participants in the study described herein.

This section has suggested several recommendations based on interview data analysis. The next section will look at how the research findings might act as a spring-board for further research.

\section{Imelications for Eurther Research}

Some research has been done to support the recommendation that orientation programs should be arranged in a Maslow-like way according to new-faculty needs (Eison, 1989). Thus, a follow-up study that surveys large numbers of new faculty and asks them to name the kind of information they need before going into the classroom, and the kind of information they need as the semester progresses, would be valuable. In essence, this study asks faculty to describe the ideal orientation module. This same study could incorporate another approach and list orientation items (for example, introductions to administrators; explanation of the evaluation and tenure processes; and tour of the campus). New faculty would place these items within time frames 
indicated on the survey. The findings would help instructional administrators to order orientation information in a hierarchy better meeting the needs of new faculty. Another possible study could focus on this researcher's contention that the type of previous experience, specifically with the community college system, affects the types of problems experienced the first year of hire. The participants for the study described herein were drawn from three colleges. Even though all qualifying and willing participants were included at two of the sites, a relatively small " $n$ " of nineteen was available. A follow-up study would use the challenges articulated by interviewees in this study. These challenges would be arranged on a likert scale and participants would be asked to rank challenges in order of their importance or impact during the first year of hire. This larger study would probably encompass more participants with full-time community college teaching backgrounds, and participants with very limited teaching backgrounds, such as teaching assistants. Both of these teaching categories were underrepresented in this study.

In summary, the community college system is the fastest growing segment of American education (Cohen, 1986). This study is an exploratory and descriptive study meant to provide community college leaders at all institutional levels with information to help them better meet the needs of new faculty members. Working within an institution is a learning 
process. This study tapped into participant learning and pulled together common challenges that are potentially beneficial to anyone interested in helping assist a new faculty member.

Foster (1986) wrote that "the school leader puts critical theory to work--through reflection, understanding, and education" (p. 13). The findings presented in this study contribute significantly to the understanding of new-faculty needs. The recommendations present a plan for putting theory into action. Perhaps this dissertation will educate administrators and encourage them to reflect about their present method of indoctrinating new faculty. It is hoped that as a result of this study and its findings, education theory is embellished in such a way so as to encourage action on the part of college leadership. 


\section{REFERENCES}

Blair, S. M. \& Bercik, J. T. (1987). Teacher induction: A survey of experienced teachers. (Report No. SP 030 892). ERIC Document Reproduction Service No. ED 303455. Bleyer, D. R. (1979). Higher education's omission: The preparation of community college teachers. community College Review, 6 , 46-51.

Boccia, J. A. (1989). Beginning teachers speak out: A study ef professional concerns in the first three years of teaching. (Report No. TM 014 505). -San Francisco, CA: American Educational Research Association. (ERIC Document Reproduction Service No. ED 316 555).

Borg, W. R., \& Gall, M. D. (1983). Educatienal research: An introduction (4th ed.). New York: Iongman.

Brawer, E. B. (1968). Personality characteristics of college and university faculty: Imolications for the community cellege. D.C.: American Association of Junior Colleges. (ERIC Document Reproduction Service No. ED 026 408). Cohen, A. M. (1971). A constant variable, new perspectives on the cemmunity college. San Francisco: Jossey-Bass. Cohen, A. M. \& Brawer, F. B. (1977). The two-year college instructor today. New York: Praeger. Cohen, A. M. \& Brawer, F. B. (1982). The american community college. San Francisco: Jossey-Bass. 
Cohen, A. M., Lombardi, J.\& Brawer, F. B. (1977). Eellege respends to community demands. San Francisco: JosseyBass.

Collins, C. C. (1971). The induction of community college instructors: An internship model (Report No. JC 720 000). Berkeley: University of California. (ERIC Document Reproduction Service No. ED 056 684).

Cross, K. P. (1981). Adults as learners. San Francisco: Jossey-Bass.

Cross, K. P. (1983). The state of the art in needs assessments. Community/Junier college Quarterly of Research and Practice, I, 195-206.

Daresh, J. C. \& Playko, M. A. (1989). Administrative mentoring: A training manual (Report No. EA 021 506). Colorado: University of Northern Colorado. (ERIC Document Reproduction Service No. ED 315 844). Doucette, D. \& Ventura-Merkel, C. (1991). Community college programs for older adults: A status report. California, Laguna Hills: A joint project of the League for Innovation in the Community College and the American Association of Retired Persons.

Eckert, R. E. \& Williams, H. Y. (1972). College faculty view themselves and their jobs. Minneapolis: University of Minnesota. 
Eison, J. A. \& Hill, H. H. (1990). Creating workshops for new faculty. The Journal for staff, Professional, and erganizational Development, 8 (4), 223-234.

Eison, J. A. (1989). Mandatory teaching effectiveness workshops for new faculty: What a difference three years make. The Journal for Staff, Professional, and Organizational Development, $I$ (2), 59-66.

Fink, L. D. (1984). The first year of college teaching. New Directions for Teaching and Iearning Series, No. 17. San Francisco: Jossey-Bass.

Fink, I. D. (1990). From the reference desk: New faculty members: The professoriate of tomorrow. The Journal for Staff, Professional, and Organizational Development, 8 (4), 235-245.

Foster, J. \& Moore, R. (1987) . A workshop for new faculty. Engineering Education, 77 (7), 748-49. Foster, W. (1986). Paradigms and promises. New York: Prometheus. Geromel, G. (1989). Effective orientation. Nation's Business, 77, 21-24. Heck, R. H. \& Blaine, D. D. (1989). The effects of a colleague-pairing induction program on the perceptions of first-year teachers and their mentors. (Report No. SP 031 382). San Francisco, CA: American Educational Research Association. (ERIC Document Reproduction Service No. ED 310 088). 
Horner, C.F. (1954). Strike the tents: The story of shautaugua. Philadelphia: Dorrace and Co. Hyener; R. H. (1982). Some guidelines for the phenomenological analysis of interview data. Unpublished manuscript, NP .

Keim, M. C. (1989). Two-year college faculty: A research update. Community cellege Review, 17 (3), 34-43.

Kelly, M. F. \& Connolly, J. (1970). exientation for faculty in junior colleges (Report No. JC 700 200). Los Angeles: University of California, Los Angeles. (ERIC Document Reproduction Service No. ED 443 323).

Kiechel, W. (1988). Love, don't lose, the newly hired. Eortune, 117, 271-273.

Knowles, A. S. (Ed.). (1970). Handbook of college and university administration (Vol. 1). New York: McGrawHill.

Koos, I. V. (1950).. Preparation for community college teaching. Journal of Higher Education, XXII, 309-317. Lewis, K. Svinicki, M. \& Stice, J. (1985). Filling the gap: Introducing new faculty to the basics of teaching. The Journal for Staff, Professional, and Organizational Development, 3 (1), 16-21. Lombardi, J. (1973). The department/division structure in the community college. Topical Paper No. 38. Los Angeles, California: ERIC Clearinghouse for Junior Colleges, University of California, Los Angeles. 
Lombardi, J. (1974). The duties and responsibilities of the department/division chairman in community colleges. Topical Paper No. 39. Los Angeles, California: ERIC Clearinghouse for Junior Colleges, University of California, Los Angeles.

Marshall, C. (1984). Appropriate criteria of trustworthiness and goodness for gualitative research on education erganizations. Paper presented at the Annual Conference of the American Educational Research Association, New Orleans, LA.

Marshall, F. (1988). Non-judgmental induction support: An investment in teacher potential (Report No. Sp 031 636). New Orleans, LA: National Conference of the National Council of States on Inservice Education. (ERIC Document Reproduction Service No. ED 313 332)

Mason, J. E. \& Bramble, W. J. (1989). Understanding and conducting research: Applications in education and the behavioral sciences (2nd ed.). New York: McGraw-Hill. McClure, M. L. (1970). A new program for the preparation of junior college faculty. (Report No. SP 005 633). Tahlequah: Northeastern State College. (ERIC Document Reproduction Service No. ED 061 183). 
MCClusky, H. Y. (1974). Adult, continuing, and community education: The shape and promise of the field. In F. C. Kintzer (Ed.), National Conference on Community Continuing Education: Alternative Approaches to Responsibility. Los Angeles: University of California, $20-25$.

Medsker, L. L., \& Tillery, D. (1971). Breaking the access barrier, a profile of two-year colleges. New York: MCGraw-Hill.

Million, S. K. (1988). Training mentors and proteges: The key to successful mentor programs. (Report No. SP 031 650). New Orleans: Annual Conference of the National Council of States on Inservice Education. (ERIC Document Reproduction Service No. ED 314 363).

Noonan, J. (1980). An institute on teaching and learning for new faculty. In, W. Nelson \& M. Siegel, (Eds.), Effective approaches to faculty development. Washington, DC: Association of American Colleges. Nowick, N. (1983). Workshop on course design and teaching styles: A model for faculty development. In M. Davis, (Ed.), To improve the academy: Resources for student, faculty, and institutional development, 2, 143-158, Stillwater, OK: The Professional and Organizational Development Network in Higher Education. Palinchak, R. S. (1973). The evolution of the community college. New Jersey: The Scarecrow Press, Inc. 
Patterson, R. A. (1971). Career patterns and educational

issues: Pennsylvania community college faculty.

University Park, Pa: Pennsylvania State University.

Peshkin, A. (1988). In search of subjectivity--one's own.

Educational Researcher, 6, 17-22.

Quisenberry, N. I. (1989). Teacher induction: An annotated

bibliography. (Report No. SP 032 129). (ERIC Document

Reproduction Service No. ED 182465$)$.

Reid, A. E., Jr. (1966). A history of the California public

junior college movement. (Doctoral Dissertation,

University of Southern California, 1966). University

Micrefilms No. 66-7081.

Roueche, J. E. (1989). Leadership for 2000: Management

report 1989-90/1 (Report No. JC 9000 157). The

Association of California Community Colleges (ERIC

Document Reproduction Service No. ED 316 290).

Ryan, K. (1986). The induction of new teachers.

Bloomington: Phi Delta Kappa Educational Foundation.

Sawma, L. M. (1989). Adding life to employee orientation. Innovation Abstracts, XI, No. 28.

Schein, E. H. (1986). Organizational culture and leadership.

San Francisco: Jossey-Bass.

Silverman, R. (1985). Staff development at Santa Monica

College (Report No. JC 860 151). Santa Monica: Santa Monica College. (ERIC Document Reproduction Service No. ED 267 853). 
Smith, M. I. (1981). No omission here: One university's program preparing community college teachers. Community College Review, . 8, 47-49.

Sutton, C. \& Zion, C. (1973). Integrated in-service development. In A. M. Cohen (Ed.), Toward a professional faculty. San Francisco: Jossey-Bass.

Tesch, R. (1984). Phenomenological studies: A critical analysis of their nature and procedures. Paper presented at the annual meeting of the American Educational Research Association, New Orleans. Thornton, J.W. (1960). The community junior college. New York: John Wiley and Sons, Inc. Turner, J. \& Boice, B. (1987). Starting at the beginning: The concerns and needs of new faculty. In J. Kurfiss, (Ed.), To improve the academy: Resources for student, faculty, and institutional development, $6,41-47$. Stillwater, OK: The Professional and Organizational Development Network in Higher Education. Turner, J. L., \& Boice, R. (1989). Experiences of new faculty. Journal of Staff, Program and Organizational Development, 7 (2), 51-57.

Waggaman, J. S. (1983). Eaculty recruitment, retention, and fair employment: obligations and epportunities. ASHEERIC/Higher Education Research Report No. 2. Washington, D.C.: Association for the Study of Higher Education. 
Wasserman, S. \& Emory, D. (1989). Issues in beginning teacher support (Report No. SP 030 981). Northridge: California State University, Northridge. (ERIC Document Reproduction Service No. ED 304 441).

Welch, C., Solkoff, N., Schimpfhauser, F. \& Henderson, N. (1988). The University at Buffalo program for new faculty. In E. Wadsworth (Ed.), Professional and organizational development network in higher education: A handbook for new practitioners, 109-113. Stillwater, OK: The Professional and Organizational Development Network in Higher Education.

Wendell, H. K. (1987). Seminars in college teaching: An approach to faculty development. College Teaching, 35 (2) , 70-71.

Wisniewski, R. (1990). Untitled article. The community, Technical, and Junior college Times, May $22,1 \& 3$. Yarger, R. D. (1982) . Changes in perceived instructionaldevelopmental needs of new part-time faculty in community colleges (Doctoral dissertation, Michigan State University, 1982). Dissertation Abstracts International, 43, 4309A. 


\section{APPENDIX A}

INITIAL CONTACT (by telephone)

Introduction: "My name is Kris Stonebreaker and I am a doctoral student at the University of San Diego. I am doing my dissertation study about the first year experiences of community college faculty."

origin of contact: "I was given your name by the Human Resource department at this college as a full-time faculty member hired in the Fall of 1989."

Request: "Would you be willing to meet with me to answer a few questions and share your perceptions? I anticipate the interview will take thirty to forty-five minutes."

Confidentiality: "The interview will be audiotaped, but confidential. I will never refer to you or your school by name in the report I write, all data will be reported in aggregate form. Although selected quotes may be transcribed to support my analysis, you will be referred to as "respondent" or "participant". The audiotape will be erased as soon as my dissertation study is accepted."

Interview is scheduled and, if requested, a copy of the interview questions are sent to the participant. 


\author{
APPENDIX B \\ UNIVERSITY OF SAN DIEGO \\ SCHOOI OF EDUCATION \\ CONSENT FORM
}

You are being asked by Kristen Stonebreaker, a doctoral candidate in the School of Education at the University of San Diego, to participate in a study of the first year experiences of full-time community college faculty. The intent of this study is to analyze problems experienced by faculty during the first year of hire and compile information that could improve institutional support and understanding of new faculty. If you agree, you are asked to take part in an informal, thirty to forty-five minute verbal interview with Kristen Stonebreaker about your first year experiences. This interview will be audiotaped and specific comments may be transcribed, though anonymously reported.

The data from the study will be analyzed and published in aggregate form to protect the anonymity of each participant. If specific comments are transcribed, the subject will be referred to as "respondent" or "participant". The researcher will be the only individual to see this consent form.

No risk or discomfort is expected as a result of participating in the study. Participation in the study is completely voluntary. There is no agreement, written or verbal, beyond that which is expressed in this consent form. You may refuse to participate or may withdraw from the study at any time without risk or penalty. Please ask any questions you may have at any time during your participation.

Thank you for your interest and cooperation.

I, the undersigned, understand the above explanations and, on that basis, I give consent to my voluntary participation in this research study.

Signature of Participant

Date:

Signature of Researcher

Date:

Signature of Witness

Date :

Done at

Date: 


\section{APPENDIX C \\ Interview Questions}

1. Tell me about your previous teaching experience.

2. Think about the challenges you experienced this past year. I'm going to mention some categories and I'd like you to describe the challenges or problems you encountered with each area:
a. Students
b. Teaching load
c. Collegial relationships
d. Administration or college governance
e. Faculty organizations

Are there any other areas that presented challenges that you would like to add to this list?

3. When dealing with the problems you just described, what was the greatest source of help to you? How did this source help you?

4. Let's assume that this college is interested in improving the support given to first year faculty. What advise would you give this institution to help it better meet the needs of first year teachers? 